\title{
Effects of the Ser326Cys polymorphism in the DNA repair OGG1 gene on cancer, cardiovascular and all-cause mortality in the PREDIMED study: Modulation by Mediterranean diet
}

Dolores Corella, $\mathrm{PhD}^{1,2}$; Judith B. Ramírez-Sabio, $\mathrm{MD}^{1,3}$, Oscar Coltell, $\mathrm{PhD}^{4,2}$, Carolina Ortega, $\mathrm{PhD}^{1,2}$, Ramón Estruch, MD, PhD ${ }^{2,5}$, Miguel A. Martínez-González, MD, PhD ${ }^{2,6}$, Jordi SalasSalvadó, MD,PhD ${ }^{2,7}$, José V. Sorlí, MD, $\mathrm{PhD}^{1,2}$, Olga Castañer, $\mathrm{PhD}^{2,8}$, Fernando Arós, MD,PhD 2,9, Franscisco J Garcia-Corte, MD ${ }^{2,10}$, Lluís Serra-Majem, MD, PhD ${ }^{2,11}$, Enrique Gómez-Gracia, MD, $\mathrm{PhD}^{12}$, Miquel Fiol, MD, $\mathrm{PhD}^{2,13}$, Xavier Pintó, MD, $\mathrm{PhD}^{2,14}$; Guillermo T Saez, $\mathrm{MD}, \mathrm{PhD}^{2,15}$, Estefanía Toledo, $\mathrm{MD}, \mathrm{PhD}^{2,6}$, Josep Basora, $\mathrm{MD}, \mathrm{PhD}^{2,7}$, Montserrat Fitó, MD,PhD ${ }^{2,8}$, Montserrat Cofán, DPharm, $\mathrm{PhD}^{2,16}$, Emilio Ros, MD,PhD ${ }^{2,16}$, José M Ordovás, PhD, $2,17,18$

${ }^{1}$ Department of Preventive Medicine and Public Health, School of Medicine, University of Valencia, Valencia, Spain; ${ }^{2}$ CIBER Fisiopatología de la Obesidad y Nutrición, Instituto de Salud Carlos III, Madrid, Spain; ${ }^{3}$ Oncology Department. Sagunto Hospital, Sagunto, Spain;

${ }^{4}$ Department of Computer Languages and Systems. School of Technology and Experimental Sciences, Universitat Jaume I, Castellón, Spain; ${ }^{5}$ Department of Internal Medicine, Hospital Clinic, IDIBAPS, Barcelona, Spain; ${ }^{6}$ Department of Preventive Medicine and Public Health, University of Navarra - Navarra Institute for Health Research (IdisNa), Pamplona, Spain; ${ }^{7}$ Human Nutrition Unit, Biochemistry and Biotechnology Department, IISPV, University Rovira i Virgili, Reus, Spain; ${ }^{8}$ Cardiovascular Risk and Nutrition Research Group, Hospital del Mar Medical Research Institute (IMIM), Barcelona, Spain; ${ }^{9}$ Department of Cardiology, OSI ARABA. University Hospital. University of the Basque Country UPV/EHU. Vitoria-Gasteiz. Spain; 
${ }^{10}$ Department of Family Medicine. Primary Care Division of Sevilla, San Pablo Healthcare Centre, Sevilla, Spain; ${ }^{11}$ Research Institute of Biomedical and Health Sciences, University of Las Palmas de Gran Canaria, Las Palmas de Gran Canaria, Spain; ${ }^{12}$ Department of Epidemiology, School of Medicine, University of Malaga, Malaga, Spain; ${ }^{13}$ Balearic Islands Health Research Institute (IdISPa), Hospital Son Espases, Palma, Spain; ${ }^{14}$ Lipids and Vascular Risk Unit, Internal Medicine, Hospital Universitario de Bellvitge , Barcelona, Spain; ${ }^{15}$ Department of Biochemistry and Molecular Biology-Service of Clinical Analysis- University of Valencia, Valencia, Spain;

${ }^{16}$ Lipid Clinic, Endocrinology and Nutrition Service, Institut d'Investigacions Biomèdiques August Pi Sunyer (IDIBAPS), Hospital Clinic, Barcelona, Spain; ${ }^{17}$ Nutrition and Genomics Laboratory, JM-USDA Human Nutrition Research Center on Aging at Tufts University, Boston, MA, USA; ${ }^{18}$ Department of Cardiovascular Epidemiology and Population Genetics, Centro Nacional de Investigaciones Cardiovasculares (CNIC), Madrid-IMDEA Alimentación, Madrid, Spain.

Abstract word count: 326

Text word count: 5347

\section{For correspondence:}

Dolores Corella, PhD

Genetic and Molecular Epidemiology Unit. Valencia University

Blasco Ibañez, 15

46010-Valencia, Spain

Tel: (+34) 963864800; Fax: (+34) 963864166; E-mail: dolores.corella@uv.es 


\section{Keywords}

Nutrigenetics, cancer, cardiovascular, mortality, vegetables.

\section{Author contributions}

Dolores Corella, José V. Sorlí, Ramón Estruch, Miguel A. Martínez-González, Jordi SalasSalvadó, Fernando Arós, Lluís Serra-Majem, Enrique Gómez-Gracia, Miquel Fiol, Montserrat Fitó, Emilio Ros and José M. Ordovás conceived the study concept and design, obtained funding, and reviewed the manuscript. Carolina Ortega-Azorin, Judith B. Ramírez-Sabio, Olga Castañer, Guillermo T. Saez, Franscisco J Garcia-Corte, Josep Basora, Montserrat Cofán and Estefanía Toledo acquired data and reviewed the manuscript. Oscar Coltell designed and developed the data management system, elaborated tables and figures, administered the documentation management system and managed all revision and submission procedures. Dolores Corella, Oscar Coltell and José M. Ordovás analyzed and interpreted data, wrote the manuscript, and reviewed/edited the manuscript. Emilio Ros edited the manuscript. Dolores Corella is the guarantor of this work and, as such, had full access to all the data in the study and takes responsibility for the integrity of the data and the accuracy of the data analysis.

\section{Funding/financial disclosures}

This work was supported by the Spanish Ministry of Health (Instituto de Salud Carlos III) and the Ministerio de Economía y Competitividad-Fondo Europeo de Desarrollo Regional (FEDER) under Grants [numbers CIBER 06/03, CNIC-06/2007, PI06-1326, PI07-0954, PI11/02505, SAF2009-12304, AGL2010-22319-C03-03, PI13/00728, PRX14/00527, SAF2016-80532-R, and PI13/01848]; the University Jaume I under Grant [numbers P1-1B2013-54 and COGRUP/2016/06]; Fundació La Marató de TV3 under Grant [number 538/U/2016]; and the 
U.S. Department of Agriculture Research Service, USA under Grants [numbers 53-K06-5-10 and 58-1950-9-001].

\section{Conflict of interest disclosures}

The authors declare no conflict of interest. The founding sponsors had no role in establishing work goals; in the collection, analyses or interpretation of data; in the writing of the manuscript; nor in the decision to publish the results. 
1 Effects of the Ser326Cys polymorphism in the DNA repair OGG1 gene on cancer,

2 cardiovascular and all-cause mortality in the PREDIMED study: Modulation by the

3 Mediterranean diet

4

5

6

7 Research Question: Is the lower DNA-repair capacity genotype (homozygous individuals for the

8 Cys326 allele) in the OGG1-rs1052133 (Ser326Cys) polymorphism associated with cancer

9 mortality or other causes and are these associations modulated by Mediterranean diet (MedDiet)

10 or vegetable intake?

11 Key findings: In the PREDIMED dietary intervention trial including 7,170 participants, the

12 Cys326Cys-OGG1 genotype was associated with higher total mortality, mainly cardiovascular

13 mortality. For cardiovascular and total mortality, no statistically significant interactions were

14 found with the MedDiet intervention. However, when vegetable intake was considered,

15 significant interactions decreasing the risk for cardiovascular mortality in homozygous

16 individuals with higher intake were detected.

\section{ABSTRACT}

22 Background: Oxidatively induced DNA damage, an important factor in cancer etiology, is

23 repaired by oxyguanine glycosylase 1 (OGG1). The lower repair capacity genotype (homozygote

24 Cys326Cys) in the OGG1-rs1052133 (Ser326Cys) polymorphism has been associated with

25 cancer risk. However, no information is available in relation to cancer mortality, other causes of 
26 death and modulation by diet.

27 Objective: Our aim was to evaluate the association of the OGG1-rs1052133 with total, cancer

28 and cardiovascular (CVD) mortality and to analyze its modulation by the Mediterranean diet

29 (MedDiet), focusing especially on total vegetable intake as one of the main characteristics of this

30 diet.

31 Design: PREDIMED is a randomized, controlled trial conducted in Spain from 2003 to 2010.

32 Participants/setting: Study participants $(n=7,170)$ were at high risk for CVD and aged 55-80

33 years.

34. Intervention: Participants were randomly allocated to two groups with a MedDiet intervention

35 or to a control diet.

36 Main Outcome measures: Main outcomes were all-cause, cancer and CVD mortality after a

37 median follow-up of 4.8 years.

38 Statistical analyses: Multivariable-adjusted Cox regression models were fitted.

39 Results: 318 deaths were detected (cancer $=127, \mathrm{CVD}=81$ and others $=110)$. Cys326Cys

40 individuals (prevalence 4.2\%) presented higher total mortality rates than Ser326-carriers

41 ( $\mathrm{P}=0.009)$. The multivariable-adjusted Hazard Ratio (HR) for Cys326Cys versus Ser326-carriers

42 was 1.69 (95\%CI:1.09-2.62); $\mathrm{P}=0.018$. This association was greater for CVD mortality

$43(\mathrm{P}=0.001)$. No relationship was detected for cancer mortality in the whole population (HR:1.07;

$4495 \%$ CI:0.47-2.45; $\mathrm{P}=0.867)$, but a significant age interaction $(\mathrm{P}=0.048)$ was observed as

45 Cys326Cys was associated with cancer mortality in participants $<66.5$ years $(\mathrm{P}=0.029)$.

46 Recessive effects limited our ability to investigate Cys326Cys*diet interactions for cancer

47 mortality. No statistically significant interactions for total or CVD mortality were found for the

48 MedDiet intervention. However, significant protective interactions for CVD mortality were found

49 for vegetable intake (HR-interaction per standard deviation: 0.42;95\%CI:0.18-0.98, $\mathrm{P}=0.046$ ). 
50 Conclusions: In this population, the Cys326Cys-OGG1 genotype was associated with all-cause

51 mortality, mainly CVD instead of cancer mortality. Additional studies are needed to provide

52 further evidence on its dietary modulation.

53

54

55 
DNA molecules are exposed to the attack of DNA-damaging agents ${ }^{1}$, among them

reactive oxygen species (ROS) $)^{2}$. Oxidatively induced DNA damage can be both mutagenic and

59 cytotoxic $^{3}$ and has been implicated in the etiology of cancer ${ }^{4}$, neurodegenerative diseases ${ }^{5}$ and

60 overall aging ${ }^{6}$. Hydroxyl radicals preferentially react with the C8 atom of purines in DNA to

61 generate 8-oxo-7,8-dihydroguanine (8-oxoG), 8-oxo-7,8-dihydroadenine (8-oxoA) and

62 formamidopyrimidines (Fapy) ${ }^{7}$. The accumulation of unrepaired DNA damage can cause genetic

63 instability and has deleterious effects on cell function ${ }^{8} .8-0 x o G$ is a critical mutagenic lesion

64 because of its propensity to mispair with A during DNA replication ${ }^{7}$. Repair of oxidatively

65 damaged bases occurs primarily via the DNA base excision repair (BER) pathway ${ }^{2}$. In the first

66 step of this type of repair, damaged bases are removed from DNA by DNA glycosylases ${ }^{9}$. The

67 oxyguanine glycosylase 1 (OGG1) is the human DNA glycosylase responsible for removal of the

68 highly mutagenic 8-oxoG from DNA ${ }^{7}$. The OGG1 gene is located in chromosome $3 \mathrm{p} 26.2$ and

69 this region has frequently been detected as deleted in various tumors suggesting the loss of this

70 gene as a possible contributor to carcinogenesis ${ }^{7,10-13}$.

71 The most studied polymorphism in the human OGG1 gene is the rs1052133 (Ser326Cys),

72 a $\mathrm{C}$ to $\mathrm{G}$ transversion at nucleotide 1245 in exon 7 , leading to a serine to cysteine substitution at

73 residue $326^{14}$. This variant is functional and it has been shown that the Cys 326 protein has

74. weaker 8-hydroxyguanine-repair capacity than the Ser326 protein ${ }^{15-17}$. The deactivation of the

75 OGG1 gene or the presence of a less active variant such as the Cys326 may lead to a higher risk

76 of cancer and oxidation-related pathologies ${ }^{7,13,18}$. Consequently, this polymorphism has been

77 analyzed as a risk factor in several cancers ${ }^{19-25}$ (i.e., breast, prostate, lung, colorectal, aero

78 digestive, gastric, bladder). The results of meta-analyses for each location are heterogeneous ${ }^{21-25}$,

79 but where there is more consensus is in the significant association of the Ser326Cys 
80 polymorphism with greater overall risk of cancer when the different locations are pooled ${ }^{26,27}$.

81 Thus, Zou et $\mathrm{al}^{26}$ in a meta-analysis including 152 case-control studies, concluded that the Cys

82 variant was strongly associated with higher cancer risk. Interestingly, the cancer risk was higher

83 in homozygous individuals for the Cys variant, suggesting a recessive pattern. This observation

84 agrees with several functional studies showing that only homozygous carriers of the Cys allele

85 showed a significantly lower DNA repair activity compared to Ser326Ser ${ }^{16,18}$. A potential source

86 of the observed heterogeneity found among studies may be the exposure to different

87 environmental factors ${ }^{28-31}$ (i.e. mainly vegetable intake and other dietary factors).

88 The Ser326Cys OGG1 polymorphism has also been associated with a greater risk of

89 atherosclerosis ${ }^{32,33}$ and incidence of cardiovascular diseases ${ }^{34,35}$, although there have been very

90 few studies that have specifically focused on cardiovascular phenotypes.

91 Whereas many studies have analyzed the influence of the OGG1 Ser326Cys

92 polymorphism on cancer risk, few have analyzed its influence on mortality due to cancer.

93 Moreover, if the OGG1 gene also makes an important contribution to other pathologies, such as

94 cardiovascular diseases, there is compelling interest in knowing whether, in the same cohort, this

95 gene has a greater influence on mortality due to cancer or on mortality due to cardiovascular

96 disease. The aims were, first, to analyze the influence of the OGG1 Ser326Cys polymorphism on

97 cancer mortality, cardiovascular mortality and on total mortality in a high cardiovascular risk

98 Mediterranean population and second to investigate the possible modulation by diet by analyzing

99 the Mediterranean diet (MedDiet) intervention as well as focusing on total vegetable intake as

100 one of the main characteristics of the MedDiet.

101

\section{METHODS}

103 The present study was conducted within the framework of the PREDIMED trial, the 
104 design of which has been described in detail elsewhere ${ }^{36}$. Briefly, the PREDIMED study is a

105 multicenter, randomized and controlled clinical trial aimed at assessing the effects of the

106 MedDiet on the primary cardiovascular prevention ${ }^{37}$. This study was registered at controlled-

107 trials.com (http://www.controlledtrials.com/ISRCTN35739639). Here, 7,170 participants (from

108 a total of 7,447) were included from whom DNA was isolated and the OGG1-rs1052133

109 (Ser326Cys) polymorphism determined. Briefly, from October 2003 to June 2009 physicians in

110 Primary Care Centers located in several Spanish regions selected high-cardiovascular risk

111 participants. Eligible participants were community-dwelling adults at high cardiovascular risk

112 (55-80 years for men; 60-80 years for women) who met at least one of two criteria: diabetes or 3

113 or more cardiovascular risk factors (hypertension, dyslipidemia, overweight or obesity, current

114 smoking, or a family history of premature coronary heart disease $)^{36}$. Exclusion criteria were the

115 presence of any severe chronic illness, previous history of cardiovascular diseases, alcohol or

116 drug abuse, and history of allergy or intolerance to olive oil or nuts. Hence, individuals with

117 incident cancer undergoing treatment were excluded, but individuals that reported having had

118 some form of cancer in previous years but who had no clinical signs of cancer at the time of

119 enrollment were not excluded.

120 Participants were randomly assigned to these interventions: a MedDiet (2 groups, one

121 supplemented with extra-virgin olive oil and the other with nuts) and a control group (advised to

122 follow a low-fat diet). Randomization was performed by means of a computer-generated

123 random-number sequence (randomly assigned in a 1:1:1 ratio to one of three groups).

124 Participants assigned to both MedDiet groups received intensive training to follow the MedDiet

125 and allotments of either extra-virgin olive oil (1L/week) or mixed nuts $(30 \mathrm{~g} / \mathrm{d})$ throughout the

126 entire study time period, whereas those assigned to the control diet were instructed to reduce the

127 intake of all types of fat ${ }^{37}$. Because both MedDiet intervention groups had a similar effect ${ }^{37}$, 
128 these groups were pooled and analyzed together. The primary end point of the PREDIMED trial

129 was cardiovascular disease incidence, including a composite endpoint comprised of myocardial

130 infarction incidence, stroke incidence and cardiovascular death. Total and cause-specific

131 mortality were considered as secondary endpoints. In this study, total and cause-specific

132 mortality will be analyzed, focusing on mortality due to cancer and cardiovascular events.

133 The Institutional Review Board of each participating center approved the study protocol,

134 and all participants provided written informed consent. The trial was stopped following the

135 statistical analysis of data obtained up to December 2010, due to early evidence of the benefit of

136 the MedDiet on the prevention of major cardiovascular events ${ }^{37}$. This study is based on the data

137 obtained from this follow-up period (median follow-up of 4.8 years) with dietary intervention

138 throughout the entire study time period.

140 Demographic, clinical, anthropometric and dietary measurements

141 The baseline examination included assessment of standard cardiovascular risk factors,

142 medication use, socio-demographic factors and lifestyle variables by validated

143 questionnaires ${ }^{36,38,39}$. Adherence to the MedDiet was measured by a validated 14-item

144 questionnaire ${ }^{38}$. Food and beverage consumption was reported using a validated 137-item

145 semiquantitative food-frequency questionnaire (FFQ) ${ }^{39}$. Dietary data from the FFQ were

146 obtained for 7,122 participants. Weight and height were measured with calibrated manual or

147 digital scales and a wall-mounted stadiometer, respectively ${ }^{36}$. Body mass index (BMI) was

148 calculated as $\mathrm{kg} / \mathrm{m}^{2}$.

149

150 Biochemical determinations, DNA extraction and genotyping

$151 \quad$ Fasting glucose and lipids were measured as previously described ${ }^{40}$. Biochemical 
152 measures were available for nearly 7000 participants at baseline. Genomic DNA was extracted

153 from buffy-coat and the OGG1-rs1052133 (Ser326Cys) polymorphism was genotyped in the

154 whole cohort with DNA available on a 7900HT Sequence Detection System (Applied

155 Biosystems, FosterCity, CA, USA) using a fluorescent allelic discrimination TaqManTM assay.

156 Valid genotype results for 7,170 participants were obtained. Genotype frequencies did not

157 deviate from Hardy-Weinberg equilibrium expectations $(\mathrm{P}=0.882)$.

159 Outcomes and Follow-up

The end points of interest in the present analysis were cancer mortality, cardiovascular

161 mortality and all-cause mortality after the follow-up period. We used the following 4 sources of

162 information to identify deaths: contacts with families of participants, contacts with general

163 practitioners who were responsible for the routine clinical care of participants, yearly

164 consultation of the National Death Index, and a comprehensive yearly review of medical records

165 of all participants by medical doctors who were blinded with respect to the group allocation and

166 all nutritional information. All medical records related to endpoints were examined by the Event

167 Adjudication Committee, whose members were unaware of the dietary information ${ }^{37}$. Only

168 endpoints that were confirmed by the Event Adjudication Committee were included in the

169 analyses. In this follow-up, all deaths detected in the 7,170 patients analyzed (those that had

170 genotype OGG1 data), and that occurred between 1 October 2003 and 1 December 2010 were

171 included: Total deaths $(n=318)$, per total cancer $(n=127)$ and per cardiovascular diseases $(n=81)$.

\section{Statistical analyses}

174 The OGG1-rs1052133 polymorphism was first tested as codominant with the three 175 genotypes considered and taking into account the Ser326Ser genotype as reference. Given that, in 
176 the total and cause-specific association models, the effects of the Ser326Ser and Ser326Cys

177 genotypes were similar and no statistically significant differences were found between them,

178 carriers of the Ser326 allele were grouped together and compared to those of Cys326Cys

179 participants (recessive model). Triglycerides were log-transformed for statistical analyses.

180 Vegetable intake was standardized for further Cox regression analyses. ANOVA tests were used

181 to compare means of continuous variables by the OGG1 polymorphism and cause of death. The

182 association between the OGG1-rs1052133 polymorphism and the different causes of death were

183 analyzed by means of the Chi Square test, using both codominant and recessive models.

184 To examine the longitudinal association between the OGG1-rs 1052133 polymorphism

185 and mortality (separated models for all-cause, cancer and cardiovascular mortality) in the 4.8

186 years median follow-up, Cox regression models were used with length of follow-up as the

187 primary time variable. The exposure time was calculated as the time between randomization and

188 the date at death, the date when the last interview was completed on 1 December 2010,

189 whichever came first. Firstly, the mortality rate for the 3 genotypes and fitted codominant models

190 were estimated. After having checked that there were no significant differences between the

191 estimates of genotypes Ser326Ser and Ser326Cys, both genotypes were grouped together as Ser-

192 carriers. This group was used as the category of reference and homozygous Cys326Cys were

193 compared with it using a recessive model. Hazard Ratios (HRs) with 95\% CIs for the OGG1-

194 rs1052133 genotypes were estimated. Models were sequentially adjusted for covariates as

195 indicted. Model 1 was adjusted for age, sex, field center and dietary intervention group (three

196 groups). Model 2 was additionally adjusted for type-2 diabetes, BMI, and self-reported personal

197 history of a previously diagnosed cancer at baseline. Model 3 was additionally adjusted for

198 alcohol consumption, smoking, physical activity, hypertension, dyslipidemia, medications (lipid-

199 lowering, hypoglycemic, and antihypertensive drugs) adherence to MedDiet and total energy 
intake in the models analyzing diet.

201 Also evaluated was the heterogeneity of the OGG1-rs1052133 associations with mortality

202 by age groups. Two age groups were considered, taking into account the median age of the

203 population (66.5 years). Formal tests for the interaction between the OGG1 polymorphism and

204 age group in determining mortality (total, cancer and cardiovascular deaths) were carried out by

205 analyzing the product term of these variables in the corresponding hierarchical Cox regression

206 model. Testing this interaction in a Cox regression model estimates the departure from

207 multiplicativity instead of the departure from additivity ${ }^{41,42}$. Stratified analyses of both age

208 groups were carried out. Finally, the modulation by Mediterranean diet of the associations

209 between the OGG1-rs1052133 polymorphism and CVD mortality and total mortality were

210 evaluated. First of all, the randomized and controlled clinical trial design (MedDiet intervention

211 compared with the control diet) was used. Analyses were based on the intent-to-treat principle.

212 Models were sequentially adjusted for covariates as previously indicated (model 1, model 2 and

213 model 3). Multiplicative tests for the interaction between the OGG1 polymorphism and MedDiet

214 intervention in determining mortality (total and cardiovascular mortality) were carried out in the

215 multivariable adjusted Cox regression models. Stratified analyses by dietary intervention groups

216 were undertaken.

217 In addition to the modulation by MedDiet intervention, as secondary analysis, the

218 influence of total vegetable intake at baseline (observational cohort design) was investigated, as

219 vegetables are a main food of the MedDiet previously reported to statistically interact with the

220 OGG1-rs1052133 polymorphism ${ }^{28}$. Vegetable intake was used as categorical (dichotomously,

221 using the consumption median of the population as the cut-off point) and as a continuous variable

222 (in grams/day). For the continuous variable, the HRs of mortality per standard deviation (SD) of

223 vegetable intake were calculated. Multivariable Cox regression models were fitted and interaction 
224 terms analyzed. Taking into account the relevance of age in mortality, dietary interactions by age

225 groups were also explored.

226 Kaplan-Meier survival curves were plotted to estimate the probability of remaining free of

227 mortality (total or causes) during follow-up. Statistical analyses were performed with the IBM

228 SPSS Statistics version $24.0^{43}$. All tests were 2 -tailed, and $P<0.05$ was considered statistically

229 significant.

230

231 RESULTS

232 Descriptive characteristics of participants and causes of death by OGG1-rs1052133

233 (Ser326Cys) genotypes

234 Table 1 presents demographic, clinical and lifestyle characteristics at baseline of the

235 7,170 PREDIMED participants according to their genotype in the OGG1-rs1052133 (Ser326Cys)

236 polymorphism. Overall, there were no differences among genotypes in the main characteristics

237 analyzed. The only statistically significant differences were observed in BMI and triglycerides.

238 The OGG1 genotypes were equally distributed into the three dietary intervention groups.

239 Following 4.8 years of median follow-up, 318 deaths were confirmed, of which the majority were

240 from cancer $(n=127)$, followed by cardiovascular diseases $(n=81)$ and other causes $(n=110$

241 deaths). Table 2 presents the baseline characteristics of the participants depending on whether

242 participants were still alive or had died after 4.8 years of median follow-up. Within the mortality

243 group, the cause of death was also reported. The mean age at baseline of the individuals still

244 living was lower than that of the deceased. Among the deceased, the mean age was lower in those

245 who died from cancer than from cardiovascular diseases. Although, in this study, individuals with

246 a recently diagnosed cancer were not included, there were 184 participants with a prior diagnosis

247 of cancer (in any location), presumably cancer-free at enrollment according to self-reports. 
248 Greater mortality due to cancer was detected in individuals who had previously been diagnosed

249 with cancer compared to those who had not $(\mathrm{P}<0.001)$. The effect was high (HR: 5.91; 95\%CI:

$2503.52-9.92 ; \mathrm{P}<0.001$, for cancer mortality and HR: 3.13; 95\%CI: $2.04-4.80 ; \mathrm{P}<0.001$ for total

251 mortality, in model 1), so this variable was included as an adjustment variable in the later

252 multivariable Cox regression models. Table 2 also presents the frequencies of the OGG1-

253 rs1052133 polymorphism according to vital status and cause of death. In the model in which the

254 three genotypes were analyzed separately, genotypes Ser326Ser and Ser326Cys were distributed

255 equally among the different causes of death $(\mathrm{P}>0.05)$. However, the Cys326Cys genotype

256 differed in some causes of death $(\mathrm{P}<0.05)$ and when comparing total mortality. In the recessive

257 model, the Cys326Cys genotype was associated with all-cause mortality $(\mathrm{P}=0.006)$, being more

258 frequent in mortality cases than in non-cases, while the highest frequency of the Cys326Cys

259 genotype occurred in cardiovascular diseases. The detection of this recessive effect will limit the

260 statistical power of subsequent comparisons.

261

262 Multivariable-adjusted associations of the OGG1-rs1052133 polymorphism with total, 263 cancer and cardiovascular mortality

264 Table 3 presents mortality rates, HRs and 95\% CI for the OGG1 genotypes for total,

265 cancer and cardiovascular mortality after 4.8 years of median follow-up (maximum follow-up of

2667.4 years) obtained in the multivariable-adjusted Cox-regression models (model 1, model 2 and

267 model 3). For all-cause mortality, higher total mortality rates in homozygous Cys326Cys were

268 detected in comparison with the other genotypes (Ser-carriers): HR for total mortality in

269 Cys326Cys participants: 1.77 ; $95 \%$ CI: $1.16-2.71 ; \mathrm{P}=0.009$, in the minimally adjusted model 1

270 (adjusted for sex, age, field center and dietary intervention group). After additional multivariable

271 adjustment in model 3 (including BMI, diabetes, self-reported history of cancer, smoking, 
272 drinking, physical activity, adherence to the MedDiet and medications), this association remained

273 statistically significant (HR: 1.69; 95\% CI:1.09-2.62; P=0.018). On analyzing the specific causes

274 of death separately, a strong association was found between the OGG1 polymorphism and

275 cardiovascular mortality (HR: 3.31; 95\% CI: 1.68-6.53; $\mathrm{P}=0.001$ for Cys363Cys participants in

276 comparison with Ser-carriers in the multivariable adjusted model 3). However, on studying the

277 overall association of the OGG- rs1052133 polymorphism with mortality from cancer, even

278 though in this population there were more deaths from cancer than from cardiovascular diseases

279 ( $n=127$ compared to $n=81$, respectively), no statistically significant association was detected in

280 the case of cancer. Also using a recessive model, the HR for cancer mortality in Cys326Cys

281 individuals in comparison with Ser-carriers was $1.07 ; 95 \% \mathrm{CI}$ : 0.47-2.45; $\mathrm{P}=0.867$. Comparing

282 the Cys326Cys with the Ser326Ser, the results of no association were similar. Figure 1 shows

283 Kaplan Meier curves of cumulative mortality-free survival for total mortality (A) cardiovascular

284 (B) and cancer mortality (C) by the three OGG1-rs1052133 genotypes in the whole population.

285 Bearing in mind that mortality from cancer occurs in younger individuals, whereas mortality

286 from cardiovascular diseases occurs in older individuals, the influence of the age group (two

287 groups according to the median of age at baseline) on the associations of the OGG1

288 polymorphism was analyzed (Table 4). It was observed that there was heterogeneity by age in

289 the association of the OGG1-rs1052133 polymorphism with cancer mortality, in such a way that

290 in younger individuals (less than 66.5 years at baseline), the Cys326Cys genotype was

291 significantly associated (Table 4 and Figure 1D) with higher cancer mortality (HR: 3.27; 95\%CI:

292 1.13-9.47; P=0.029 for Cy362Cys participants compared to Ser-carriers in model 3).

293 Nevertheless, in those 66.5 years or older, no significant association was detected $(\mathrm{P}=0.285)$. One

294 important limitation in this estimation is the small number of cases of fatal cancer in Cys326Cys

295 homozygous individuals. However, despite this limitation of sample size, a statistically 
296 significant interaction term between age group and the OGG1 polymorphism on cancer mortality

297 (P-interaction=0.048 in model 3) was obtained. Cancer deaths $(n=41)$ in participants $<66.5$ years

298 at baseline were as follows: lung (26.8\%), pancreatic-biliary (12.2\%), colorectal (9.8\%), gastric

299 (7.3\%), prostate (7.3\%), liver (2.4\%), ovary-endometrial (2.4\%) and other locations (31.7\%).

$300 \quad$ For cardiovascular mortality, an opposite effect was observed. Most of the mortality and

301 the greatest association with the OGG1 polymorphism occurred in the older age group $(>=66.5$

302 years). However, on testing the interaction per age, no statistically significant value ( $\mathrm{P}=0.234$ in

303 model 3) was detected, as although the risk is lower in the younger group, the association goes in

304 the same direction. Neither was a statistically significant heterogeneity of the association of the

305 polymorphism by age group with total mortality found (P-interaction=0.570 in model 3).

307 Effect of the MedDiet intervention on the association between the OGG1-rs1052133

308 polymorphism and mortality

309 The influence that diet had on modulating the Cys326Cys genotype association with

310 greater mortality (total and cardiovascular) was analyzed. Modulation by diet in mortality due to

311 cancer was not analyzed owing to the small number of Cys326Cys participants dying from cancer

$312(\mathrm{n}=6)$ and, besides, an additional interaction per age group had been detected that presents

313 heterogeneity and limits statistical power still further ( $\mathrm{n}=4$ cancer deaths in Cys326Cys

314 participants aged $<66.5$ years at baseline). Table 5 presents the results of the modulation of the

315 Cys326Cys genotype associations with total mortality and per cardiovascular diseases depending

316 on the intervention with MedDiet (both groups considered jointly) or the control diet. For total

317 mortality, no statistically significant interaction between the genotype and intervention with

318 MedDiet (P-interaction=0.752, in model 3) was found. Likewise, for cardiovascular mortality,

319 the interaction term between intervention with the MedDiet and the OGG1 polymorphism did not 
reach statistical significance $(\mathrm{P}$-interaction $=0.181$ in model 1 and $\mathrm{P}$-interaction $=0.200$ in model

$3213)$.

In subgroup analysis by age we found that for total mortality the interaction term between

323 the OGG1 polymorphism and MedDiet intervention reached statistical significance in

324 participants aged $\geq 66.5$ years in model 1 (P-interaction=0.049). However, in model 3 after

325 additional multivariable adjustment (HR for Cys326Cys in the MedDiet group: 1.30; 95\%CI:

326 0.65-2.60; $\mathrm{P}=0.451$ versus HR for Cys326Cys in the control group: 2.99; 95\%CI:1.34-6.67;

$327 \mathrm{P}=0.008$, in the stratified analysis), the statistical significance of the interaction term for this

328 comparison was lost (P-interaction=0.112). Likewise, for cardiovascular mortality, the interaction

329 terms in this group did not reach statistical significance (P-interaction=0.082 in model 1 and

$330 \quad \mathrm{P}=0.086$ in model 3).

\section{Effect of vegetable intake on the association between the OGG1-rs1052133 polymorphism} 333 and mortality

Finally, vegetable intake at baseline (Table 6) was focused on. No statistically significant

335 interactions between vegetable intake and the OGG1-rs1055133 polymorphism in determining

336 total mortality were found ( $\mathrm{P}$-interaction $=0.491$ for categorical and $\mathrm{P}=0.367$ for continuous

337 variables in model 3). However, when cardiovascular mortality was analyzed, a statistically

338 significant interaction term between vegetable intake (as continuous variable) and the OGG1

339 polymorphism in determining cardiovascular mortality in the whole population (P-

340 interaction $=0.035$ in model 1 , which remained statistically significant in model 3, P-

341 interaction=0.046) was detected. According to this interaction, a high vegetable intake decreased

342 the risk of cardiovascular mortality more in Cys326Cys individuals than in Ser-carriers: HR-

343 interaction: 0.42 ; 95\%CI: $0.18-0.98$, per 1 SD $(150 \mathrm{~g} / \mathrm{d})$ of vegetable intake. When vegetable 
344 intake was analyzed as dichotomous (2 groups according to the median intake of the population),

345 it was observed that the Cys326Cys genotype was associated with higher cardiovascular

346 mortality in comparison with Ser-carriers $(\mathrm{P}<0.001$ in model 3), in participants having a low

347 vegetable intake $(<314 \mathrm{~g} / \mathrm{d})$. However, Cys326Cys participants having a high vegetable intake

348 (>=314 grams/d) did not present a statistically significant higher risk of cardiovascular mortality

349 in comparison with Ser-carriers $(\mathrm{P}=0.671)$. Although the $\mathrm{P}$-value for the corresponding

350 interaction term did not reach the statistical significance $(\mathrm{P}=0.101$, in model 3$)$ for the

351 dichotomous variable of vegetable intake, due to very small number of Cys326Cys participants,

352 this observation was supported by the statistical significance of the interaction term between the

353 OGG1 genotype and vegetable intake as continuous variable.

354 In the subgroup analysis in participants aged $\geq 66.5$ years, a statistically significant

355 interaction between vegetable intake (as continuous variable) and the OGG1 polymorphism in

356 determining total mortality (HR-interaction: 0.49 ; 95\%CI: $0.25-0.96 ; \mathrm{P}=0.037$ per SD, in model

357 3) was obtained. Also in participants aged $\geq 66.5$ years, the interaction term between vegetable

358 intake (as continuous) and the OGG1 polymorphism was statistically significant for

359 cardiovascular mortality (HR-interaction: 0.30; 95\%CI: 0.11-0.83; $\mathrm{P}=0.021$, per SD, in model 3).

361 DISCUSSION

In this study the influence of the OGG1-rs1052133 (Ser326Cys) polymorphism on total

363 and cause-specific mortality, including cancer and cardiovascular mortality, has been

364 longitudinally investigated in a cohort of older participants in the PREDIMED study. This

365 polymorphism, in which the Cys326Cys genotype has been associated with a lower damage

366 repair capacity in $\mathrm{DNA}^{15-17}$, has also been associated with a higher risk of cancer and other

367 diseases related to DNA repair in many studies ${ }^{7,18-27}$. However, no previous study has jointly 
analyzed the impact of this polymorphism on total mortality and in a comparative manner on

369 cancer and cardiovascular mortality in the same population. In this sense, the current study results

370 on the contribution of the OGG1-rs1052133 genotypes to the mortality rate per 1,000 (person-

371 years of follow-up) as well as to the mortality risk, are novel.

373 polymorphism with all-cause mortality has been found; the mortality risk of Cys326Cys

374 participants being 1.69 times higher than that of the other genotypes (recessive effects). This

375 association was stronger for cardiovascular mortality, whereas for cancer mortality no association

376 was detected for the OGG1-rs1052133 polymorphism in the whole population. The association

377 with cancer was only statistically significant in participants aged less than 66.5 years at baseline.

378 The observation of recessive effects limited the statistical power of our subsequent gene-diet

379 interaction analyses ${ }^{44}$. Moreover, the small number of Cys326Cys participants may have led to an

380 overestimation of effect size in some associations, in the so-called winner's curse ${ }^{45}$. This term

381 refers to the phenomenon by which studies that first find evidence of an effect often provide

382 inflated estimates of the size of that effect ${ }^{45}$. Effect inflation is worse for small, low-powered

383 studies. However, despite some inflation of the effects, a true association effect can be present in

384 large, well-designed prospective studies ${ }^{46,47}$. Therefore, it can be assumed that some associations

385 found in the present study, mainly those obtained in subgroup analyses, may be overestimated

386 due to the low number of Cys326Cys carriers. Supporting a true association, the current study's

387 results are consistent with dozens of previous studies in animal models that show harmful health

388 effects associated with a reduced DNA repair capacity of the variants in the OGG1 gene ${ }^{7,48-52}$

389 They are also consistent with work in humans that associate the Cys326 variant with a higher risk

390 of cancer ${ }^{11-27}$ as well as other diseases ${ }^{2,33,53-55}$. However, as far as we know, no previous study has

391 estimated the influence of this polymorphism on total mortality. One of the factors that can help 
explain the strong associations found between the OGG- rs1052133 polymorphism and mortality

393 is that a high cardiovascular risk population is being analyzed. In a subsample of this

394. population ${ }^{56}$, higher levels of the DNA-damaged product 8-oxo-7'8'-dihydro-2'-deoxyguanosine

395 (8-oxo-dG) were previously detected in nucleated blood cells in comparison with participants

396 from the general population (not at high cardiovascular risk) paired by age and sex (5.61 \pm 1.17 in

397 PREDIMED participants versus 3.71 \pm 0.65 in non-high cardiovascular risk participants,

398 expressed as $\left.8-0 x 0-\mathrm{dG} / 10^{6} \mathrm{dG} ; \mathrm{P}<0.001\right)$. This is relevant considering the reports on the impaired

399 DNA repair capacity of the Cys326Cys variant being enhanced under conditions of oxidative

400 stress $^{17}$, largely increasing the risk of oxidative patothologies ${ }^{18}$.

401 Although several studies have analyzed the influence of the OGG1-rs1052133 on cancer

402 incidence or prevalence ${ }^{19-27}$, no previous study at the population level has analyzed the

403 association of such polymorphism with cancer mortality. Some studies have analyzed the

404 influence of the OGG1-rs1052133 polymorphism on the survival or prognosis of selected groups

405 of patients receiving cancer treatment ${ }^{57,58}$, but there are no estimates of mortality rates in a

406 general population cohort. Although in our cohort at high cardiovascular risk deaths from cancer

407 outnumbered those from cardiovascular disease, no association between the Cys326Cys genotype

408 and cancer mortality was observed in the whole population. However, a strong association was

409 detected between the Cys326Cys risk genotype and cardiovascular mortality. Although in

410 comparison to studies that have examined the possible association between the OGG1-rs1052133

411 polymorphism and cancer ${ }^{18-31}$, very few have examined its association with cardiovascular

412 disease ${ }^{33-35,54}$, studies in animal models on OGG1 function strongly support this

413 association $^{32,59,60}$. Thus, in a study by Tumurkhuu et $\mathrm{al}^{32}$ in Ogg1(-/-) mice, the authors observed

414 a more atherogenic profile of the different markers analyzed in comparison with mice with a

415 normal Ogg1 gene expression. In the Ogg1 (-/-) mice, higher serum IL-1 $\beta$ and IL-18 levels, 
416 higher oxidized mitochondrial DNA and higher inflammasome activation were detected. Taking

417 into account that OGG1 is the major DNA glycosylase responsible for removing the most

418 abundant products of oxidative DNA damage, it is not surprising to find a pro-atherosclerotic

419 phenotype in mice deficient in the ogg1 gene. Interestingly, these authors also reported higher

420 levels of triglycerides in deficient mice $^{32}$. Interestingly, in PREDIMED participants, higher

421 plasma triglycerides in Cys326Cys participants were also detected. Overall, OGG1 may play a

422 protective role in atherogenesis by preventing excessive inflammasome activation ${ }^{32}$. In humans,

423 most of the few studies carried out on cardiovascular disease $\mathrm{e}^{33-35,54}$ also have found a higher risk

424 associated with the Cys326 allele. Thus, Izzoti et $\mathrm{al}^{33}$ examined the survival of patients with

425 severe atherosclerosis and concluded that those bearing the OGG1 homozygous slow

426 polymorphism had increased levels of two bulky DNA adducts, being more susceptible than

427 other individuals to the genotoxic consequences of oxidative stress in the arterial wall. Orhan et

$428 \mathrm{al}^{35}$ also concluded that the OGG1-rs 1052133 played a role in stroke risk, and Shyu et $\mathrm{al}^{34}$

429 reported an effect of smoking increasing stroke risk in Chinese carriers of the Cys allele. The

430 present study results showing a strong association between the OGG1-rs1052133 polymorphism

431 and cardiovascular mortality in Cys326Cys homozygotes concur with these findings. Because a

432 high cardiovascular risk population was analyzed, it is no surprise that the association of the

433 OGG1-rs1052133 polymorphism was stronger for cardiovascular disease mortality than cancer

434 mortality.

435 Of note, cardiovascular mortality is also gaining in importance in cancer patients ${ }^{61,62}$, as

436 their increased survival allows them to reach older ages in which their risk of death may be

437 determined by cardiovascular risk factors. For instance, in a population-based cohort study

438 conducted among 98,999 women diagnosed with early-stage breast cancer, those 66 years or

439 older who survived 5 years or more after diagnosis had cardiovascular disease as the leading 
cause of death, exceeding breast cancer mortality rates at 10 years after diagnosis ${ }^{62}$.

Age is an important determinant of mortality. The mean age of the deceased due to cancer in the PREDIMED cohort was significantly lower than the mean age of the deceased due to cardiovascular diseases. Interestingly, it was found that, in the younger age group ( $<66.5$ years), the OGG1-rs1052133 polymorphism was indeed more associated with cancer mortality than cardiovascular mortality. Conversely, the association of the OGG1 polymorphism with higher cardiovascular mortality was mainly detected in the older age group. This may be explained by the age-dependent reduction of the DNA repair efficiency, enhanced in Cys326Cys participants ${ }^{2}$. In younger participants, the increased cancer mortality associated with this polymorphism may be associated with an additional genetic component related to specific locations (i.e. BRCA1, BRCA2, etc.) in which the OGG1-risk genotype may contribute to enhance the genome instability that increases the risk, being also considered as a cancer risk modifier ${ }^{63}$.

When analyzing gene-diet interactions, sample size limitations due to the recessive effect and the relatively low prevalence of the Cys326Cys genotype in this population (4.2\%) prevented examination of the dietary modulation of the effects of the OGG1-rs1052133 polymorphism on cancer mortality (only 6 deaths with the Cys326Cys genotype were detected). Related to this, it is known that the prevalence of the OGG1-rs1052133 polymorphism is lower in white (1.8-8.6 per cent Cys326Cys participants) than in Asian populations (13.4-38.2 per cent Cys326Cys) ${ }^{64}$. However, bearing this limitation in mind, it was possible to explore dietary modulation in determining all-cause mortality and cardiovascular mortality (involving more homozygotes). When testing whether intervention with the MedDiet modulated the effect of the Cys326Cys genotype increasing total mortality a statistically significant interaction was not found. Likewise, for cardiovascular mortality in the whole population, the interaction term between the OGG1 genotype and MedDiet did not reach statistical significance. Further studies are needed to provide 
464 further evidence on the modulation of the MedDiet intervention on the effects of the OGG1-

465 rs1052133 polymorphism on mortality risk.

466 The MedDiet is characterized by a high intake of vegetables ${ }^{37,65}$. Vegetables are very rich

467 in antioxidants and other phytochemicals ${ }^{66,67}$ that may contribute to a better DNA protection from

468 oxidation in Cys326Cys individuals who have less capacity for repairing it ${ }^{68-70}$. Recent meta-

469 analyses ${ }^{71,72}$ have shown that high vegetable consumption is associated with a lower risk of all-

470 cause mortality $^{71,72}$, particularly cardiovascular mortality ${ }^{72}$. Although no previous study has

471 analyzed the interaction between vegetable consumption and the OGG1-rs1052133

472 polymorphism in determining total or cause-specific mortality, this gene-diet interaction on

473 cancer risk has been analyzed in some reports ${ }^{28,73,74}$. Noteworthy is the work of Sorensen et $\mathrm{al}^{28}$,

474 showing a statistically significant interaction between vegetable intake and the OGG1-rs1052133

475 polymorphism on lung cancer incidence, with a 54\% decrease in cancer risk per 50\% increase in

476 vegetable consumption among Cys326Cys participants and no decrease in risk among Ser326Ser

477 or Ser326Cys individuals. In the PREDIMED study, a similar interaction between theOGG1-

478 rs1052133 polymorphism and vegetable intake in determining cardiovascular mortality in the

479 whole population has been detected, in such a way that a high vegetable intake was associated

480 with a greater reduction of cardiovascular mortality in Cys326Cys homozygotes in comparison

481 with Ser-carriers. This effect had a similar trend for total mortality but only reached significance

482 in the older age group.

\section{CONCLUSIONS}

484 In conclusion, in a Mediterranean population at high cardiovascular disease risk, an association of

485 the OGG1-rs1052133 polymorphism with higher total and cardiovascular mortality in

486 Cys326Cys homozygotes has been found, while higher cancer mortality was only detected in the

487 lower age group. Recessive effects limited the study of gene-diet interactions. Non-significant 
488 interaction terms were detected for the MedDiet intervention. Nevertheless, a significant gene-

489 diet interaction with vegetable consumption in determining cardiovascular mortality has been

490 observed, in such a way that higher consumption decreased the risk more in Cys326Cys

491 participants, supporting the beneficial role of the antioxidant compounds present in vegetables in

492 providing protection from DNA damage and mortality risk in genetically susceptible individuals.

493 However, replication of these results in other studies is needed to confirm these associations and

494 dietary modulations.

495 
498 1. Müller S. DNA damage-inducing compounds: unraveling their pleiotropic effects using high 499 throughput sequencing. Curr Med Chem. 2017;(in press).

500 2. Whitaker AM, Schaich MA, Smith MS, et al. Base excision repair of oxidative DNA damage:

501 from mechanism to disease. Front Biosci. 2017;22:1493-1522.

502 3. Schermerhorn KM, Delaney S. A chemical and kinetic perspective on base excision repair of 503 DNA. Acc Chem Res. 2014;47.1238-1246.

504 4. Kryston TB, Georgiev AB, Pissis P, Georgakilas AG. Role of oxidative stress and DNA 505 damage in human carcinogenesis. Mutat Res. 2011;711:193-201.

506 5. Leandro GS, Sykora P, Bohr VA. The impact of base excision DNA repair in age-related 507 neurodegenerative diseases. Mutat Res. 2015;776:31-39.

508 6. Mikkelsen L, Bialkowski K, Risom L, et al. Aging and defense against generation of 8-oxo509 7,8-dihydro-2'-deoxyguanosine in DNA. Free Radic Biol Med. 2009;47.608-615.

510 7. Boiteux S, Coste F, Castaing B. Repair of 8-oxo-7,8-dihydroguanine in prokaryotic and 511 eukaryotic cells: Properties and biological roles of the Fpg and OGG1 DNA N-glycosylases.

$512 \quad$ Free Radic Biol Med. 2016;(in press).

513 8. Seifermann M, Epe B. Oxidatively generated base modifications in DNA: Not only

514 carcinogenic risk factor but also regulatory mark? Free Radic Biol Med. 2016;S0891-

$515 \quad 5849(16) 31041-31043$.

516 9. D'Errico M, Parlanti E, Pascucci B, et al. Single nucleotide polymorphisms in DNA

517 glycosylases: From function to disease. Free Radic Biol Med. 2017; 107:278-291. 
10. Hagiwara A, Kitajima Y, Sato S, Miyazaki K. Allelic loss of the DNA repair gene OGG1

519 against oxidative damage in esophageal squamous cell carcinoma. Oncol Rep. 2005;13:10095201016.

521 11. Shinmura K, Yokota J. The OGG1 gene encodes a repair enzyme for oxidatively damaged

522 DNA and is involved in human carcinogenesis. Antioxid Redox Signal. 2001;3:597-609.

523 12. Arcand SL, Provencher D, Mes-Masson AM, Tonin PN. OGG1 Cys326 variant, allelic 524 imbalance of chromosome band 3p25.3 and TP53 mutations in ovarian cancer. Int J Oncol. $525 \quad 2005 ; 27: 1315-1320$.

526 13. Boiteux S, Radicella JP. The human OGG1 gene: structure, functions, and its implication in 527 the process of carcinogenesis. Arch Biochem Biophys. 2000;377.1-8.

528 14. Dherin C, Radicella JP, Dizdaroglu M, Boiteux S. Excision of oxidatively damaged DNA 529 bases by the human alpha-hOgg1 protein and the polymorphic alpha-hOgg1(Ser326Cys) protein 530 which is frequently found in human populations. Nucleic Acids Res. 1999;27:4001-4007.

531 15. Smart DJ, Chipman JK, Hodges NJ. Activity of OGG1 variants in the repair of pro-oxidant532 induced 8-oxo-2'-deoxyguanosine. DNA Repair (Amst). 2006;5.1337-1345.

533 16. Bravard A, Vacher M, Moritz E, et al. Oxidation status of human OGG1-S326C

534 polymorphic variant determines cellular DNA repair capacity. Cancer Res. 2009;69.3642-3649.

535 17. Kershaw RM, Hodges NJ. Repair of oxidative DNA damage is delayed in the Ser326Cys

536 polymorphic variant of the base excision repair protein OGG1. Mutagenesis. 2012;27:501-510.

537 18. Simonelli V, Camerini S, Mazzei F, et al. Genotype-phenotype analysis of S326C OGG1 538 polymorphism: a risk factor for oxidative pathologies. Free Radic Biol Med. 2013;63:401-409.

539 19. Mittal RD, Mandal RK, Gangwar R. Base excision repair pathway genes polymorphism in 
$540 \quad$ Prostate and bladder cancer risk in North Indian population. Mech Ageing Dev. 2012;133:127-

$541 \quad 132$.

542 20. Costa EF, Santos ES, Liutti VT, et al. Association between polymorphisms in genes related

543 to DNA base-excision repair with risk and prognosis of oropharyngeal squamous cell

544 carcinoma. J Cancer Res Clin Oncol. 2016;142:1917-1926.

545 21. Das S, Nath S, Bhowmik A, et al. Association between OGG1 Ser326Cys polymorphism

546 and risk of upper aero-digestive tract and gastrointestinal cancers: a meta-analysis. Springerplus

$547 \quad 2016 ; 5: 227$.

548 22. Peng Q, Lu Y, Lao X, et al. Association between OGG1 Ser326Cys and APEX1 Asp148Glu 549 polymorphisms and breast cancer risk: a meta-analysis. Diagn Pathol. 2014;9:108.

550 23. Xu Z, Yu L, Zhang X. Association between the hOGG1 Ser326Cys polymorphism and lung

551 cancer susceptibility: a meta-analysis based on 22,475 subjects. Diagn Pathol. 2013;8:144.

552 24. Zhang Y, He BS, Pan YQ, et al. Association of OGG1 Ser326Cys polymorphism with

553 colorectal cancer risk: a meta-analysis. Int J Colorectal Dis. 2011;26:1525-1530.

554 25. Wang Z, Gan L, Nie W, Geng Y. The OGG1 Ser326Cys polymorphism and the risk of

555 esophageal cancer: a meta-analysis. Genet Test Mol Biomarkers. 2013;17:780-785.

556 26. Zou H, Li Q, Xia W, et al. Association between the OGG1 Ser326Cys Polymorphism and

557 Cancer Risk: Evidence from 152 Case-Control Studies. J Cancer. 2016;7:1273-1280.

558 27. Wei B, Zhou Y, Xu Z, et al. The effect of hOGG1 Ser326Cys polymorphism on cancer risk:

559 evidence from a meta-analysis. PLoS One. 2011;6:e27545.

560 28. Sørensen M, Raaschou-Nielsen O, Hansen RD, et al. Interactions between the OGG1

561 Ser326Cys polymorphism and intake of fruit and vegetables in relation to lung cancer. Free 
Radic Res. 2006;40:885-891.

563 29. Brevik A, Joshi AD, Corral R, et al. Polymorphisms in base excision repair genes as 564 colorectal cancer risk factors and modifiers of the effect of diets high in red meat. Cancer 565 Epidemiol Biomarkers Prev. 2010;19:3167-3173.

566 30. Nordström T, Van Blarigan EL, Ngo V, et al. Associations between circulating carotenoids, 567 genomic instability and the risk of high-grade Prostate cancer. Prostate. 2016;76:339-348.

568 31. Corral R, Lewinger JP, Van Den Berg D, et al. Comprehensive analyses of DNA repair 569 pathways, smoking and bladder cancer risk in Los Angeles and Shanghai. Int J Cancer. $570 \quad 2014 ; 135.335-347$.

571 32. Tumurkhuu G, Shimada K, Dagvadorj J, et al. Ogg1-Dependent DNA Repair Regulates 572 NLRP3 Inflammasome and Prevents Atherosclerosis. Circ Res. 2016;119:e76-90.

573 33. Izzotti A, Piana A, Minniti G, et al. Survival of atherosclerotic patients as related to 574 oxidative stress and gene polymorphisms. Mutat Res. 2007;621:119-128.

575 34. Shyu HY, Shieh JC, Ji-Ho L, et al. Polymorphisms of DNA repair pathway genes and 576 cigarette smoking in relation to susceptibility to large artery atherosclerotic stroke among ethnic 577 Chinese in Taiwan. J Atheroscler Thromb. 2012;19:316-325.

578 35. Orhan G, Elkama A, Mungan SÖ, et al. The impact of detoxifying and repair gene 579 polymorphisms on oxidative stress in ischemic stroke. Neurol Sci. 2016;37:955-961.

580 36. Martínez-González MÁ, Corella D, Salas-Salvadó J, Ros E, et al. Cohort profile: design and 581 methods of the PREDIMED study. Int J Epidemiol. 2012;41:377-385.

582 37. Estruch R, Ros E, Salas-Salvadó J, et al. Primary prevention of cardiovascular disease with a 583 Mediterranean diet. N Engl J Med. 2013;368:1279-1290. 
584 38. Schröder H, Fitó M, Estruch R, et al. A short screener is valid for assessing Mediterranean

585 diet adherence among older Spanish men and women. J Nutr. 2011;141:1140-1145.

586 39. Fernández-Ballart JD, Piñol JL, Zazpe I, et al. Relative validity of a semi-quantitative food-

587 frequency questionnaire in an elderly Mediterranean population of Spain. Br J Nutr.

$588 \quad 2010 ; 103: 1808-1816$.

589 40. Estruch R, Martínez-González MA, Corella D, et al. Effects of a Mediterranean-style diet on 590 cardiovascular risk factors: a randomized trial. Ann Intern Med. 2006;145:1-11.

591 41. Hosmer DW, Lemeshow S. Confidence interval estimation of interaction. Epidemiology.

$592 \quad 1992 ; 3: 452-456$.

593 42. Knol MJ, van der Tweel I, Grobbee DE, et al. Estimating interaction on an additive scale

594 between continuous determinants in a logistic regression model. Int J Epidemiol. 2007;36:1111-

5951118.

596 43. IBM Corp. Released 2016. IBM SPSS Statistics for Windows, Version 24.0. Armonk, NY:

597 IBM Corp.

598 44. Dempfle A, Scherag A, Hein R, et al. Gene-environment interactions for complex traits:

599 definitions, methodological requirements and challenges. Eur J Hum Genet. 2008;16:1164-

$600 \quad 1172$.

601 45. Ioannidis JP. Why most discovered true associations are inflated. Epidemiology.

$602 \quad 2008 ; 19: 640-648$.

603 46. Xiao R, Boehnke M. Quantifying and correcting for the winner's curse in genetic association 604 studies. Genet Epidemiol. 2009;33:453-462.

605 47. Poirier JG, Faye LL, Dimitromanolakis A, et al. Resampling to Address the Winner's Curse 
606 in Genetic Association Analysis of Time to Event. Genet Epidemiol. 2015;39:518-528.

607 48. Yuzefovych LV, Kahn AG, Schuler MA, et al. Mitochondrial DNA Repair through OGG1

608 Activity Attenuates Breast Cancer Progression and Metastasis. Cancer Res. 2016;76.30-34.

609 49. Yuzefovych LV, Schuler AM, Chen J, et al. Alteration of mitochondrial function and insulin

610 sensitivity in primary mouse skeletal muscle cells isolated from transgenic and knockout mice:

611 role of ogg1. Endocrinology. 2013;154:2640-2649.

612 50. Bjørge MD, Hildrestrand GA, Scheffler K, et al. Synergistic Actions of Ogg1 and Mutyh

613 DNA Glycosylases Modulate Anxiety-like Behavior in Mice. Cell Rep. 2015;13.2671-2678.

614 51. Sampath H. Oxidative DNA damage in disease--insights gained from base excision repair

615 glycosylase-deficient mouse models. Environ Mol Mutagen. 2014;55:689-703.

616 52. Lee YL, Obiako B, Gorodnya OM, et al. Mitochondrial DNA Damage Initiates Acute Lung

617 Injury and Multi-Organ System Failure Evoked in Rats by Intra-Tracheal Pseudomonas

618 Aeruginosa. Shock. 2017;48(1):54-60.

619 53. Karahalil B, Orhan G, Ak F. The impact of detoxifying and repair gene polymorphisms and

620 the levels of serum ROS in the susceptibility to multiple sclerosis. Clin Neurol Neurosurg.

$621 \quad 2015 ; 139: 288-394$.

622 54. Gokkusu C, Cakmakoglu B, Dasdemir S, et al. Association between genetic variants of

623 DNA repair genes and coronary artery disease. Genet Test Mol Biomarkers. 2013;17:307-313.

624 55. Jacob KD, Noren Hooten N, Tadokoro T, et al. Alzheimer's disease-associated

625 polymorphisms in human OGG1 alter catalytic activity and sensitize cells to DNA damage. Free

626 Radic Biol Med. 2013;63:115-125.

627 56. Fandos M, Corella D, Guillén M, et al. Impact of cardiovascular risk factors on oxidative 
628 stress and DNA damage in a high risk Mediterranean population. Free Radic Res.

$6292009 ; 43: 1179-1186$.

630 57. Costa EF, Santos ES, Liutti VT, et al. Association between polymorphisms in genes related

631 to DNA base-excision repair with risk and prognosis of oropharyngeal squamous cell

632 carcinoma. J Cancer Res Clin Oncol. 2016;142:1917-1926.

633 58. Peng Y, Li Z, Zhang S, et al. Association of DNA base excision repair genes (OGG1, APE1

634 and XRCC1) polymorphisms with outcome to platinum-based chemotherapy in advanced

635 nonsmall-cell lung cancer patients. Int J Cancer. 2014;135.2687-2696.

636 59. Tian F, Li J, Liu XW, et al. Age-dependent accumulation of mitochondrial DNA deletions in

637 the aortic root of atherosclerosis-prone apolipoprotein E-knockout mice. Arch Gerontol Geriatr.

$638 \quad 2016 ; 63: 72-77$.

639 60. Wang J, Wang Q, Watson LJ, et al. Cardiac overexpression of 8-oxoguanine DNA

640 glycosylase 1 protects mitochondrial DNA and reduces cardiac fibrosis following transaortic

641 constriction. Am J Physiol Heart Circ Physiol. 2011;301:H2073- H2080.

642 61. Patnaik JL, Byers T, DiGuiseppi C, et al. Cardiovascular disease competes with breast

643 cancer as the leading cause of death for older females diagnosed with breast cancer: a

644 retrospective cohort study. Breast Cancer Res. 2011;13:R64.

645 62. Abdel-Qadir H, Austin PC, Lee DS, et al. A Population-Based Study of Cardiovascular

646 Mortality Following Early-Stage Breast Cancer. JAMA Cardiol. 2017;2:88-93.

647 63. Benitez-Buelga C, Vaclová T, Ferreira S, et al. Molecular insights into the OGG1 gene, a

648 cancer risk modifier in BRCA1 and BRCA2 mutations carriers. Oncotarget. 2016;7:25815-

64925825.

650 64. Hung RJ, Hall J, Brennan P, et al. Genetic polymorphisms in the base excision repair 
651 pathway and cancer risk: a HuGE review. Am J Epidemiol. 2005;162:925-942.

652 65. Corella D, Ordovás JM. How does the Mediterranean diet promote cardiovascular health?

653 Current progress toward molecular mechanisms: gene-diet interactions at the genomic,

654 transcriptomic, and epigenomic levels provide novel insights into new mechanisms. Bioessays.

$655 \quad 2014 ; 36: 526-537$.

656 66. Landete JM. Dietary intake of natural antioxidants: vitamins and polyphenols. Crit Rev Food

657 Sci Nutr. 2013;53:706-721.

658 67. Cilla A, Alegría A, Attanzio A, et al. Dietary phytochemicals in the protection against

659 oxysterol-induced damage. Chem Phys Lipids. 2017; S0009-3084(16)30189-X.

660 68. Kuo CY, Zupkó I, Chang FR, et al. Dietary flavonoid derivatives enhance chemotherapeutic

661 effect by inhibiting the DNA damage response pathway. Toxicol Appl Pharmacol. 2016;311:99-

662105.

663 69. Faust D, Nikolova T, Wätjen W, et al. The Brassica-derived phytochemical indolo[3,2-

664 b]carbazole protects against oxidative DNA damage by aryl hydrocarbon receptor activation.

665 Arch Toxicol. 2017;91:967-982.

666 70. George VC, Dellaire G, Rupasinghe HP. Plant flavonoids in cancer chemoprevention: role

667 in genome stability. J Nutr Biochem. 2016;45:1-14.

668 71. Aune D, Giovannucci E, Boffetta P, et al. Fruit and vegetable intake and the risk of

669 cardiovascular disease, total cancer and all-cause mortality-a systematic review and dose-

670 response meta-analysis of prospective studies. Int J Epidemiol. 2017;(in press).

671 72. Nguyen B, Ding D, Mihrshahi S. Fruit and vegetable consumption and psychological

672 distress: cross-sectional and longitudinal analyses based on a large Australian sample. BMJ

673 Open. 2017;7:e014201. 
674 73. Takezaki T, Gao CM, Wu JZ, et al. hOGG1 Ser(326)Cys polymorphism and modification

675 by environmental factors of stomach cancer risk in Chinese. Int J Cancer. 2002;99:624-627.

676 74. Kelemen LE, Wang SS, Lim U, et al. Vegetables- and antioxidant-related nutrients, genetic

677 susceptibility, and non-Hodgkin lymphoma risk. Cancer Causes Control. 2008;19:491-503.

678 


\section{LEGEND TO FIGURE}

Figure 1: Cumulative mortality-free survival by the OGG1-rs1052133 (Ser326Cys)

polymorphism for total mortality in the whole population (A), cardiovascular mortality in the whole population (B), cancer mortality in the whole population $(\mathbf{C})$ and cancer mortality in participants aged less than 66.5 years (D). Kaplan-Meier curves were depicted for the three genotypes, the one letter code was used for the amino acids ( $\mathrm{S}$ indicated serine and $\mathrm{C}$ indicates cysteine) ( $\mathrm{n}=4519 \mathrm{SS}, \mathrm{n}=2349 \mathrm{SC}$ and $\mathrm{n}=302 \mathrm{SS}$ in the whole population). In the group of participants aged less than 66.5 years, $\mathrm{n}=3515$ individuals. Multivariable Cox regression models were used to estimate the hazard ratios (HR) and 95\% confidence intervals (CI). Models were adjusted for age, sex, field center, dietary intervention group, type-2 diabetes, BMI, self-reported personal history of a previously diagnosed cancer at baseline, alcohol consumption, smoking, physical activity, hypertension, dyslipidemia, medications (lipid-lowering, hypoglycemic, and antihypertensive drugs) and adherence to the Mediterranean Diet. $\mathrm{P}^{1}$ indicates the $\mathrm{P}$-value for the comparison between CC and CS genotypes in the multivariable Cox regression model. HR and CI were estimated in the corresponding multivariable Cox regression models for CC participants in comparison with SS $\left(\mathrm{P}^{2}\right)$ or in comparison with SS and SC grouped together (recessive model) $\left(\mathrm{P}^{3}\right)$ for each cause of death. 


\section{CONSORT 2010 checklist of information to include when reporting a randomised trial*}

\begin{tabular}{|c|c|c|c|}
\hline Section/Topic & $\begin{array}{l}\text { Item } \\
\text { No }\end{array}$ & Checklist item & $\begin{array}{l}\text { Reported } \\
\text { on page No }\end{array}$ \\
\hline \multicolumn{4}{|l|}{ Title and abstract } \\
\hline & $1 \mathrm{a}$ & Identification as a randomised trial in the title & 1 \\
\hline & $1 b$ & Structured summary of trial design, methods, results, and conclusions (for specific guidance see CONSORT for abstracts) & $1-3$ \\
\hline \multicolumn{4}{|l|}{ Introduction } \\
\hline \multirow{2}{*}{$\begin{array}{l}\text { Background and } \\
\text { objectives }\end{array}$} & $2 a$ & Scientific background and explanation of rationale & $4-5$ \\
\hline & $2 b$ & Specific objectives or hypotheses & 5 \\
\hline \multicolumn{4}{|l|}{ Methods } \\
\hline \multirow[t]{2}{*}{ Trial design } & $3 a$ & Description of trial design (such as parallel, factorial) including allocation ratio & $5-7$ \\
\hline & $3 b$ & Important changes to methods after trial commencement (such as eligibility criteria), with reasons & $\mathrm{N} / \mathrm{A}$ \\
\hline \multirow[t]{2}{*}{ Participants } & $4 \mathrm{a}$ & Eligibility criteria for participants & 6 \\
\hline & $4 b$ & Settings and locations where the data were collected & 6 \\
\hline Interventions & 5 & $\begin{array}{l}\text { The interventions for each group with sufficient details to allow replication, including how and when they were } \\
\text { actually administered }\end{array}$ & $6-8$ \\
\hline \multirow[t]{2}{*}{ Outcomes } & $6 a$ & $\begin{array}{l}\text { Completely defined pre-specified primary and secondary outcome measures, including how and when they } \\
\text { were assessed }\end{array}$ & 8 \\
\hline & $6 b$ & Any changes to trial outcomes after the trial commenced, with reasons & $\mathrm{N} / \mathrm{A}$ \\
\hline \multirow[t]{2}{*}{ Sample size } & $7 a$ & How sample size was determined & 8 \\
\hline & $7 b$ & When applicable, explanation of any interim analyses and stopping guidelines & $8-11$ \\
\hline \multicolumn{4}{|l|}{ Randomisation: } \\
\hline \multirow{2}{*}{$\begin{array}{l}\text { Sequence } \\
\text { generation }\end{array}$} & $8 a$ & Method used to generate the random allocation sequence & 7 \\
\hline & $8 b$ & Type of randomisation; details of any restriction (such as blocking and block size) & 7 \\
\hline $\begin{array}{l}\text { Allocation } \\
\text { concealment } \\
\text { mechanism }\end{array}$ & 9 & $\begin{array}{l}\text { Mechanism used to implement the random allocation sequence (such as sequentially numbered containers), } \\
\text { describing any steps taken to conceal the sequence until interventions were assigned }\end{array}$ & 7 \\
\hline Implementation & 10 & $\begin{array}{l}\text { Who generated the random allocation sequence, who enrolled participants, and who assigned participants to } \\
\text { interventions }\end{array}$ & 7 \\
\hline Blinding & $11 \mathrm{a}$ & If done, who was blinded after assignment to interventions (for example, participants, care providers, those & 7 \\
\hline
\end{tabular}


assessing outcomes) and how

$11 \mathrm{~b}$ If relevant, description of the similarity of interventions

Statistical methods

$12 \mathrm{a}$

$12 \mathrm{~b}$

Statistical methods used to compare groups for primary and secondary outcomes

Methods for additional analyses, such as subgroup analyses and adjusted analyses

13a For each group, the numbers of participants who were randomly assigned, received intended treatment, and were analysed for the primary outcome

13b For each group, losses and exclusions after randomisation, together with reasons

14a Dates defining the periods of recruitment and follow-up

14b Why the trial ended or was stopped

15 A table showing baseline demographic and clinical characteristics for each group

Baseline data

Numbers analysed

16

For each group, number of participants (denominator) included in each analysis and whether the analysis was by original assigned groups

Outcomes and

estimation

17a For each primary and secondary outcome, results for each group, and the estimated effect size and its precision (such as $95 \%$ confidence interval)

17b For binary outcomes, presentation of both absolute and relative effect sizes is recommended

Ancillary analyses

18

Harms

\section{Discussion}

Limitations

Generalisability

Interpretation

\section{Other information}

Registration

Protocol

Funding
18 Results of any other analyses performed, including subgroup analyses and adjusted analyses, distinguishing pre-specified from exploratory

19 All important harms or unintended effects in each group (for specific guidance see CONSORT for harms)

20 Trial limitations, addressing sources of potential bias, imprecision, and, if relevant, multiplicity of analyses

21 Generalisability (external validity, applicability) of the trial findings

22 Interpretation consistent with results, balancing benefits and harms, and considering other relevant evidence

23 Registration number and name of trial registry

24 Where the full trial protocol can be accessed, if available

25 Sources of funding and other support (such as supply of drugs), role of funders
7

8-9

10-11

Table 1

N/A

8,11

7

Table 1

Table 5

Tables 3, 5

$$
\text { 11-16 }
$$

Table 6

N/A

\begin{tabular}{l}
$\frac{22}{22}$ \\
\hline 22
\end{tabular}

3,6

6 $\mathrm{N} / \mathrm{A}$

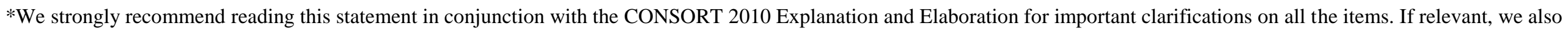

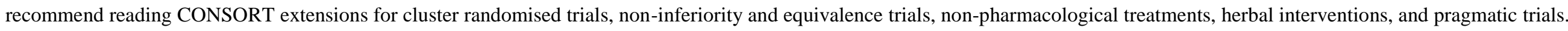
Additional extensions are forthcoming: for those and for up to date references relevant to this checklist, see www.consort-statement.org. 

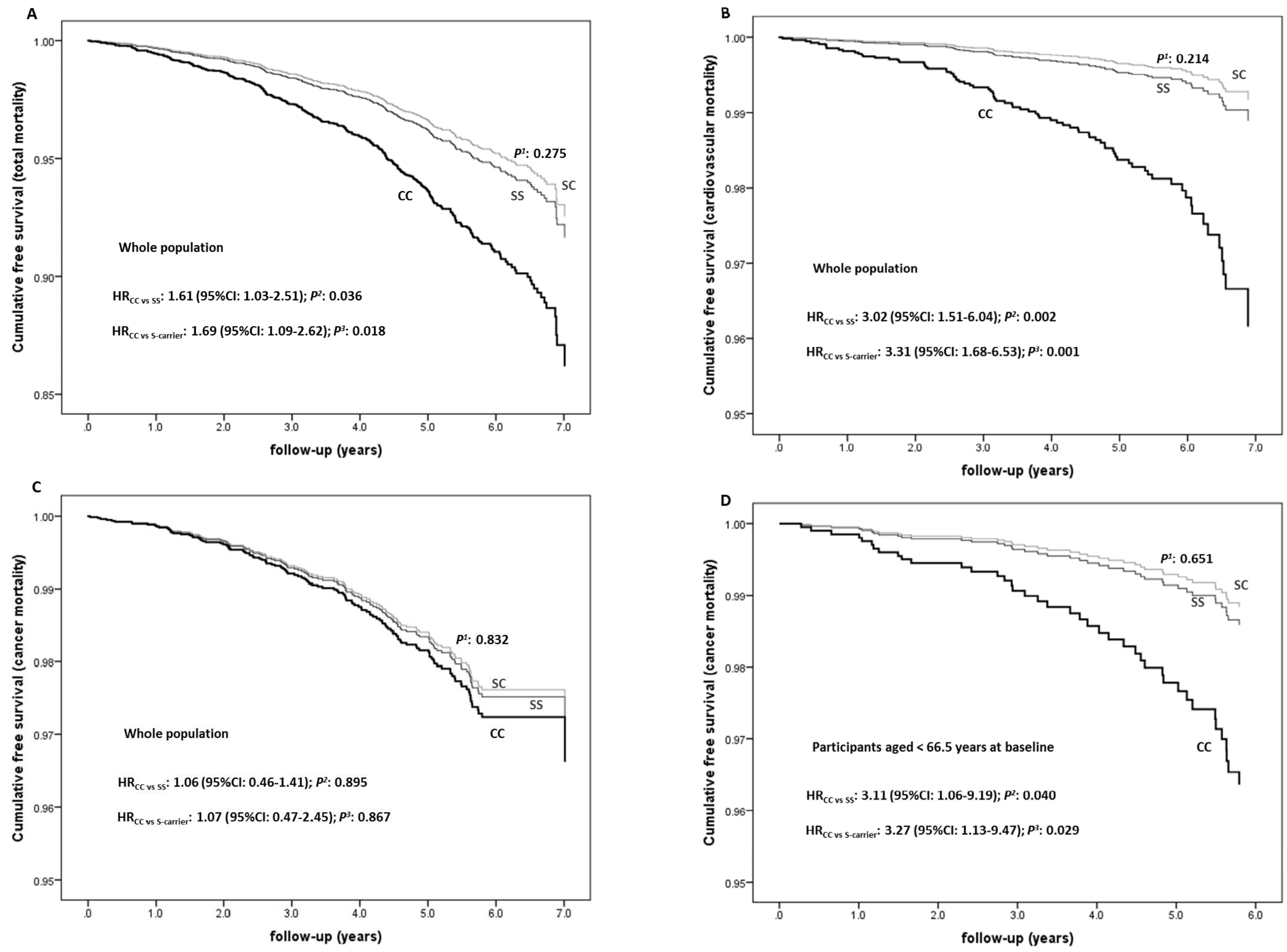
Table 1: Demographic, clinical, lifestyle and genetic characteristics of the PREDIMED study participants at baseline according to the OGG1-rs1052133 genotype $(n=7,170)^{a}$

\begin{tabular}{|c|c|c|c|c|}
\hline & $\begin{array}{c}\text { Ser326Ser } \\
(\mathrm{n}=4,519)\end{array}$ & $\begin{array}{c}\text { Ser326Cys } \\
(n=2,349)\end{array}$ & $\begin{array}{c}\text { Cys326Cys } \\
(\mathrm{n}=302)\end{array}$ & $\mathbf{P}^{\mathbf{b}}$ \\
\hline Age (years) & $66.9(6.2)$ & $67.0 \quad(6.2)$ & $67.3(6.2)$ & 0.526 \\
\hline BMI $\left(\mathrm{kg} / \mathrm{m}^{2}\right)^{\mathrm{c}}$ & $29.9(3.9)$ & $30.1 \quad(3.8)$ & $29.5(3.7)$ & 0.016 \\
\hline Female sex : n, \% & 2601 (57.6) & $1346(57.3)$ & 171 (56.6) & 0.939 \\
\hline Current smokers: n, $\%$ & 661 (14.6) & $300(12.8)$ & 41 (13.6) & 0.204 \\
\hline Type 2 diabetes: $\mathrm{n}, \%$ & 2195 (48.6) & $1127(48.0)$ & $142(47.0)$ & 0.807 \\
\hline Hypertension: n, \% & $3729(82.5)$ & $1959(83.4)$ & $248 \quad(82.1)$ & 0.626 \\
\hline Dyslipidemia: n, \% & $3259(72.1)$ & $1707 \quad(72.7)$ & $225(74.5)$ & 0.627 \\
\hline OGG1-rs1052133: n, \% & & & & 0.069 \\
\hline MedDiet with EVOO ${ }^{\mathrm{d}}$ & $1550(62.7)$ & $817 \quad(33.0)$ & $106(4.3)$ & \\
\hline MedDiet with Nuts & $1525(64.5)$ & 729 (32.6) & $110(4.7)$ & \\
\hline Control group & $1444(61.9)$ & 803 (34.4) & $86(3.7)$ & \\
\hline $\mathrm{SBP}(\mathrm{mm} \mathrm{Hg})^{\mathrm{e}}$ & $149.3(20.5)$ & $149.5(21.3)$ & $148.1(20.1)$ & 0.543 \\
\hline DBP $(\mathrm{mm} \mathrm{Hg})^{\mathrm{f}}$ & $83.3(11.0)$ & $83.4(11.0)$ & $83.9(11.2)$ & 0.676 \\
\hline Total cholesterol $(\mathrm{mg} / \mathrm{dL})^{\mathrm{g}}$ & $210.4(38.4)$ & $210.7(37.8)$ & $208.6(38.3)$ & 0.697 \\
\hline LDL-C $(\mathrm{mg} / \mathrm{dL})^{\mathrm{g}, \mathrm{h}}$ & $129.4(33.8)$ & $130.4(33.4)$ & $125.9(34.1)$ & 0.083 \\
\hline HDL-C $(\mathrm{mg} / \mathrm{dL})^{\mathrm{g}, \mathrm{i}}$ & $53.9(14.1)$ & $53.7(13.4)$ & $53.4(14.5)$ & 0.762 \\
\hline Triglycerides $(\mathrm{mg} / \mathrm{dL})^{\mathrm{j}}$ & $136.7(74.9)$ & $135.1(70.9)$ & $149.6(89.7)$ & 0.018 \\
\hline Fasting glucose $(\mathrm{mg} / \mathrm{dL})^{\mathrm{k}}$ & $121.9(40.5)$ & 122.5 & $122.6(46.1)$ & 0.838 \\
\hline Energy intake (kcal/d) & $2273(598)$ & 2275 (614) & $2321(647)$ & 0.411 \\
\hline Total fat $(\mathrm{g} / \mathrm{d})$ & $98.6(30.1)$ & $98.7(30.7)$ & $100.6(30.9)$ & 0.554 \\
\hline Saturated fat $(\mathrm{g} / \mathrm{d})$ & $25.2(9.1)$ & $25.4(9.2)$ & $25.8(10.1)$ & 0.368 \\
\hline $\operatorname{MUFA}(\mathrm{g} / \mathrm{d})^{1}$ & $48.9(16.0)$ & $48.7(16.1)$ & $49.8 \quad(15.2)$ & 0.530 \\
\hline PUFA $(\mathrm{g} / \mathrm{d})^{\mathrm{m}}$ & $15.8(7.0)$ & $15.9(7.1)$ & $16.2(6.9)$ & 0.663 \\
\hline Protein $(\mathrm{g} / \mathrm{d})$ & $92.2(22.9)$ & $93.0 \quad(23.4)$ & $94.9(25.0)$ & 0.087 \\
\hline Carbohydrate (g/d) & $239.4(79.9)$ & $238.8 \quad(82.5)$ & $245.6(87.0)$ & 0.395 \\
\hline Fat (\% energy) & $39.2(6.8)$ & $39.2(6.8)$ & $39.2(6.8)$ & 0.554 \\
\hline Carbohydrate (\% energy) & $41.9 \quad(7.2)$ & $41.7 \quad(7.1)$ & $42.0 \quad(7.0)$ & 0.395 \\
\hline Protein (\% energy) & $92.2(22.9)$ & $93.0(23.4)$ & $94.9(25.0)$ & 0.087 \\
\hline Fiber (g/d) & $25.6(9.0)$ & $25.7(9.4)$ & $26.0 \quad(8.9)$ & 0.604 \\
\hline
\end{tabular}


Vegetable $(\mathrm{g} / \mathrm{d})$

Fruit $(\mathrm{g} / \mathrm{d})$

Meat $(\mathrm{g} / \mathrm{d})$

Olive oil (g/d)

Adherence to the MedDiet (points) ${ }^{\mathrm{n}}$

Alcohol consumption (g/d)

Physical activity (MET-min/day) ${ }^{\circ}$

$\begin{array}{rlrlrll}334.9 & (146.4) & 340.9 & (156.8) & 339.8 & (151.0) & 0.281 \\ 371.2 & (206.2) & 373.2 & (210.3) & 364.7 & (192.1) & 0.780 \\ 131.8 & (60.0) & 133.1 & (58.4) & 139.7 & (62.7) & 0.075 \\ 39.5 & (17.9) & 38.8 & (18.2) & 40.2 & (16.7) & 0.266 \\ 8.6 & (2.0) & 8.6 & (1.9) & 8.7 & (1.9) & 0.969 \\ 8.4(14.2) & 8.5 & (14.4) & 7.7 & (13.0) & 0.685 \\ 233 & (239) & 230 & (243) & 228 & (225) & 0.904\end{array}$

${ }^{\mathrm{a}}$ : Values are mean(SD) for continuous variables and number (\%) for categorical variables. Food intake, total energy and macronutrients were available in 7,122 participants. Biochemical determinations were available for almost 7,000 participants (from 6,767 for LDL-C to 6,903 for Total cholesterol).

b. $P$ unadjusted.

c: BMI: body mass index;

d: EVOO: extra virgin olive oil;

e: SBP: Systolic blood pressure,

f: DBP: Diastolic blood pressure;

g: Cholesterol conversion units: $1 \mathrm{mg} / \mathrm{dL}=(1 / 38.610039) \mathrm{mmol} / \mathrm{L}$;

${ }^{\text {h: }}$ LDL-C: Low-Density Lipoprotein Cholesterol;

i: HDL-C: High-Density Lipoprotein Cholesterol;

j: Triglycerides conversion units: $1 \mathrm{mg} / \mathrm{dL}=(1 / 88.495575) \mathrm{mmol} / \mathrm{L}$;

${ }^{\mathrm{k}}$ : Glucose conversion units: $1 \mathrm{mg} / \mathrm{dL}=(1 / 18.018018) \mathrm{mmol} / \mathrm{L}$;

': MUFA: Monounsaturated fatty acids;

m: PUFA: Polyunsaturated fatty acids;

${ }^{\mathrm{n}}$ : MedDiet: Mediterranean diet; Adherence to the MedDiet (ADM) score based on a 14-point screener of adherence: a higher score represents greater $\mathrm{ADM}^{38}$;

o: MET: metabolic equivalent of physical activity in leisure time; 
Table 2: Baseline characteristics at the time of entry and future cause of death after 4.8 years of median follow-up of the PREDIMED study participants by vital status ${ }^{\mathrm{a}}$

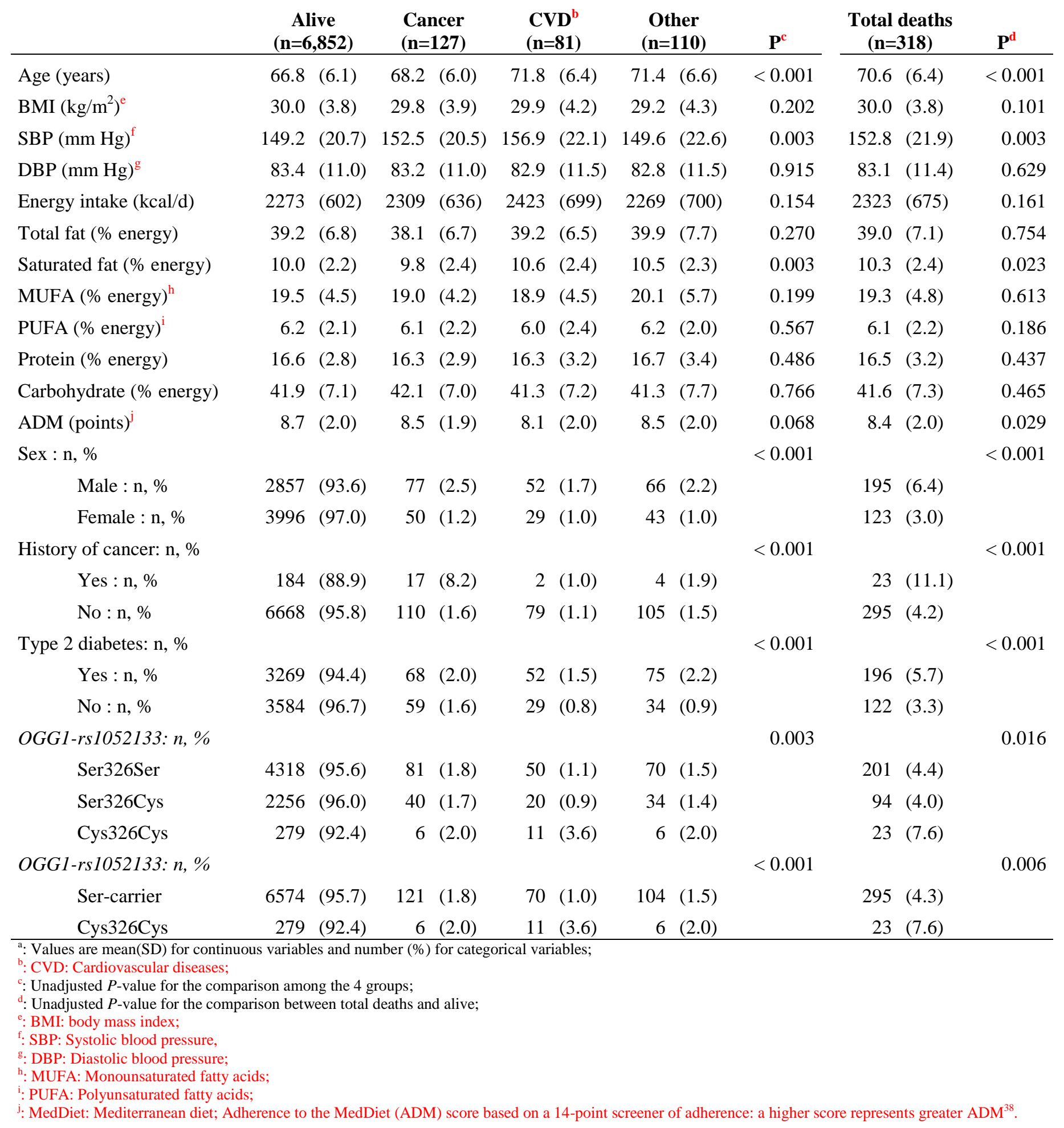


Table 3. Mortality rate and hazard ratios (HR) for total mortality and cause-specific mortality (cancer and cardiovascular) in the PREDIMED participants depending on the OGG1-rs1052133 polymorphism, after 4.8 years of median follow-up

Whole population $(n=7,170)$

\begin{tabular}{|c|c|c|c|c|c|c|c|c|c|c|}
\hline \multirow[b]{2}{*}{$\begin{array}{l}\text { Deaths / } \\
\text { person-y }\end{array}$} & \multirow[b]{2}{*}{$\begin{array}{l}\text { Mortality } \\
\text { rate }^{\mathrm{d}}\end{array}$} & \multicolumn{3}{|c|}{ Model $1^{\mathrm{a}}$} & \multicolumn{3}{|c|}{$\operatorname{Model} 2^{\mathrm{b}}$} & \multicolumn{3}{|c|}{ Model $3^{c}$} \\
\hline & & HR & $95 \%$ CI & $P$ & HR & $95 \%$ CI & $P$ & HR & $95 \%$ CI & $P$ \\
\hline
\end{tabular}

Total mortality (deaths: 318)

Codominant model

$\begin{array}{lccccccccccc}\text { Ser326Ser } & 201 / 19502 & 10.3 & 1.00 & \text { (ref.) } & 1.00 & \text { (ref.) } & & 1.00 & \text { (ref.) } & \\ \text { Ser326Cys } & 94 / 10085 & 9.3 & 0.89 & (0.70-1.14) & 0.356 & 0.88 & (0.68-1.12) & 0.285 & 0.87 & (0.68-1.03) & 0.275 \\ \text { Cys326Cys } & 23 / 1302 & 17.7 & 1.70 & (1.10-2.63) & 0.016 & 1.70 & (1.10-2.61) & 0.017 & 1.61 & (1.03-2.51) & 0.036\end{array}$

Recessive model
Ser-carriers 295/29587
$10.0 \quad 1.00 \quad$ (ref.)
1.00 (ref.)
1.00 (ref.)
Cys326Cys 23/1302
$17.7 \quad 1.77(1.16-2.71)$
$0.009 \quad 1.77(1.16-2.71)$
$\begin{array}{llll}0.009 & 1.69 & (1.09-2.62) & 0.018\end{array}$

Cancer mortality (deaths: 127)

Recessive model
Ser-carriers $\quad 121 / 29587$
$4.1 \quad 1.00 \quad$ (ref.)
1.00 (ref.)
1.00 (ref.)
Cys326Cys $\quad 6 / 1302$
4.6
$1.13(0.50-2.57)$
$0.771 \quad 1.12 \quad(0.49-2.53)$
$\begin{array}{llll}0.796 & 1.07 & (0.47-2.45) & 0.867\end{array}$

Cardiovascular mortality (deaths: 81)

Recessive model

\begin{tabular}{|c|c|c|c|c|c|c|c|c|c|}
\hline Ser-carriers & $70 / 29587$ & 2.4 & 1.00 (ref.) & & 1.00 (ref.) & & 1.00 & (ref.) & \\
\hline Cys326Cys & $11 / 1302$ & 8.4 & $3.87(2.03-7.36)$ & $<0.001$ & $3.86(2.02-7.35)$ & $<0.001$ & 3.31 & $(1.68-6.53)$ & 0.001 \\
\hline
\end{tabular}

a: Model 1: Adjusted for sex, age, center and dietary intervention group.

b: Model 2: Adjusted for variables in model 1 plus body mass index, type-2 diabetes and self-reported cancer history at baseline.

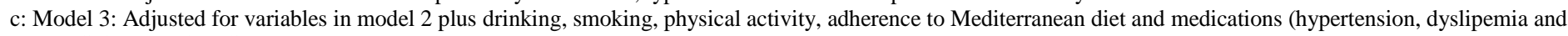
type-2 diabetes) at baseline.

d: Mortality rates were expressed per 1000 person-years of follow-up. 
Table 4. Mortality rate and hazard ratios (HR) for total mortality and cause-specific mortality (cancer and cardiovascular) in the PREDIMED participants depending on the OGG1-rs1052133 polymorphism, after 4.8 years of median follow-up. Stratified analysis by age group ${ }^{a}$

\begin{tabular}{|c|c|c|c|c|c|c|c|c|c|c|c|}
\hline & & & & Model $1^{b}$ & & & Model $2^{c}$ & & & Model $3^{\mathrm{d}}$ & \\
\hline $\begin{array}{l}\text { OGG1-rs1052133 } \\
\text { genotypes }\end{array}$ & $\begin{array}{l}\text { person- } \\
\text { years }\end{array}$ & $\begin{array}{l}\text { Mortality } \\
\text { rate }^{\mathrm{e}}\end{array}$ & HR & $95 \%$ CI & $P$ & HR & $95 \%$ CI & $P$ & HR & $95 \%$ CI & $P$ \\
\hline
\end{tabular}

Total mortality (deaths: 318)

Age group $<66.5$ years $(n=3515)$

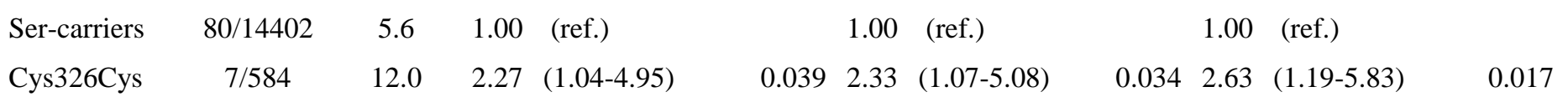

Age group $\geq 66.5$ years $(n=3655)$

\begin{tabular}{|c|c|c|c|c|c|c|c|c|c|}
\hline Ser-carriers & $215 / 15216$ & 14.1 & 1.00 (ref.) & & 1.00 (ref.) & & 1.00 & (ref.) & \\
\hline Cys326Cys & $16 / 719$ & 22.3 & $1.67(1.00-2.78)$ & 0.051 & $1.67(1.00-2.78)$ & 0.051 & 1.62 & $(0.95-2.75)$ & 0.077 \\
\hline \multicolumn{4}{|c|}{$P(\text { interaction OGG1 } x \text { Age group })^{f}$} & 0.627 & & 0.570 & & & 0.570 \\
\hline
\end{tabular}

Cancer mortality (deaths: 127)

Age group $<66.5$ years $(n=3515)$

$\begin{array}{lllll}\text { Ser-carriers } \quad 37 / 14402 & 2.6 & 1.00 & \text { (ref.) }\end{array}$

$\begin{array}{lllll}\text { Cys326Cys } \quad 4 / 584 & 6.8 & 2.77 & (0.98-7.84)\end{array}$

$\begin{array}{rlllll} & 1.00 & \text { (ref.) } & & 1.00 & \text { (ref.) } \\ 0.055 & 3.00 & (1.05-8.54) & 0.040 & 3.27 & (1.13-9.47)\end{array}$

0.029

Age group $\geq 66.5$ years $(n=3655)$

$\begin{array}{lllll}\text { Ser-carriers } & 84 / 15216 & 5.5 & 1.00 & \text { (ref.) }\end{array}$

$\begin{array}{lllll}\text { Cys326Cys } & 2 / 719 & 2.8 & 0.52 & (0.13-2.14)\end{array}$

1.00 (ref.)

1.00 (ref.)

$P$ (interaction OGG1 $x$ Age group $)^{f}$

$0.360 \quad 0.50 \quad(0.12-2.04)$

$0.333 \quad 0.46(0.11-1.90)$

0.285

0.063

0.047

0.048

Cardiovascular mortality (deaths: 81)

Age group $<66.5$ years $(\mathrm{n}=3515)$

$\begin{array}{lllll}\text { Ser-carriers } & 19 / 14402 & 1.3 & 1.00 & \text { (ref.) }\end{array}$

$\begin{array}{llllll}\text { Cys326Cys } & 1 / 584 & 1.7 & 1.37 & (0.19-10.36)\end{array}$

$\begin{array}{lll} & 1.00 & \text { (ref.) } \\ 0.761 & 1.40 & (0.19-10.60)\end{array}$

1.00 (ref.)

$0.744 \quad 1.88 \quad(0.23-15.20)$

0.555

Age group $\geq 66.5$ years $(n=3655)$

$\begin{array}{lllll}\text { Ser-carriers } & 51 / 15216 & 3.4 & 1.00 & \text { (ref.) }\end{array}$

$\begin{array}{lllll}\text { Cys326Cys } \quad 10 / 719 & 13.9 & 4.89 & (2.43-9.78)\end{array}$

$\begin{array}{lll} & 1.00 & \text { (ref.) } \\ <0.001 & 5.00 & (2.48-10.01)\end{array}$

1.00 (ref.)

$P$ (interaction OGG1 $x$ Age group $)^{f}$

0.219

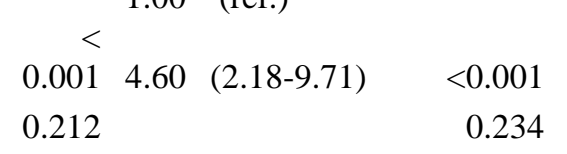

\footnotetext{
${ }^{a}$ : Age groups were considered taking into account the median of age at baseline.

${ }^{\mathrm{b}}$ : Model 1: Adjusted for sex, age, center and dietary intervention group.

: : Model 2: Adjusted for variables in model 1 plus body mass index, type-2 diabetes and self-reported cancer history at baseline.

d: Model 3: Adjusted for variables in model 2 plus drinking, smoking, physical activity, adherence to Mediterranean diet and medications (hypertension, dyslipemia and type-2 diabetes) at baseline.
} 
e: Mortality rates were expressed per 1000 person-years of follow-up.

f: $P$-values obtained for multiplicative interaction terms in the corresponding multivariable-adjusted Cox regression model. 
Table 5. Mortality rate and hazard ratios (HR) for total mortality and cardiovascular mortality in the PREDIMED participants according to the OGG1-rs1052133 polymorphism, after 4.8 years of median followup, depending on the Mediterranean diet intervention ${ }^{\mathrm{a}}$

Whole population $(n=7,170)$

OGG1-rs1052133 person- Mortality

genotypes years

rate $^{\mathrm{e}}$ HR $95 \% \mathrm{CI}$

$P \quad$ HR $95 \%$ CI

$P \quad$ HR $95 \%$ CI

$P$

Total mortality (deaths: 318)

Mediterranean diet $(n=4837)$

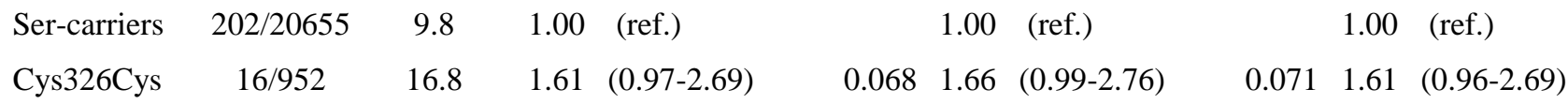

0.070

Control group $(\mathbf{n}=\mathbf{2 3 3 3})$

$\begin{array}{lllll}\text { Ser-carriers } & 93 / 8963 & 10.4 & 1.00 & \text { (ref.) }\end{array}$

$\begin{array}{llll}\text { Cys326Cys } \quad 7 / 349 & 20.0 \quad 2.09 & (0.97-4.54)\end{array}$

$\begin{array}{lll} & 1.00 & \text { (ref.) } \\ 0.061 & 2.04 & (0.94-4.43)\end{array}$

1.00 (ref.)

$P(\text { interaction OGG1 } x \text { Intervention group })^{f}$

0.469

$0.0712 .14 \quad(0.98-4.65)$

0.056

0.558

0.752

Cardiovascular mortality (deaths: 81)

Mediterranean diet $(n=4837)$

\begin{tabular}{|c|c|c|c|c|c|c|c|c|c|c|}
\hline Ser-carriers & $45 / 20655$ & 2.2 & 1.00 & (ref.) & & 1.00 (ref.) & & 1.00 & (ref.) & \\
\hline Cys326Cys & $6 / 952$ & 6.3 & 2.73 & $(1.16-6.48)$ & 0.020 & $2.78(1.17-6.60)$ & 0.020 & 2.60 & $(1.07-6.22)$ & 0.034 \\
\hline \multicolumn{11}{|c|}{ Control group $(n=2333)$} \\
\hline Ser-carriers & $25 / 8963$ & 2.8 & 1.00 & (ref.) & & 1.00 (ref.) & & 1.00 & (ref.) & \\
\hline Cys326Cys & $5 / 349$ & 14.3 & 7.48 & $(2.77-20.16)$ & $<0.001$ & $8.16(3.00-22.20)$ & $<0.001$ & 7.89 & $(2.48-25.11)$ & $<0.001$ \\
\hline \multicolumn{5}{|c|}{$(\text { interaction OGG1 } x \text { Intervention group })^{f}$} & 0.181 & & 0.167 & & & 0.200 \\
\hline
\end{tabular}

a: Both, Mediterranean diet intervention groups, were analyzed together.

${ }^{\mathrm{b}}$ : Model 1: Adjusted for sex, age, center and dietary intervention group.

c: Model 2: Adjusted for variables in model 1 plus body mass index, type-2 diabetes and self-reported cancer history at baseline.

d: Model 3: Adjusted for variables in model 2 plus drinking, smoking, physical activity, adherence to Mediterranean diet, medications (hypertension, dyslipemia and type-2 diabetes) and total energy intake at baseline. Energy intake data in Model 3 were only available in 7,122 participants.

e: Mortality rates were expressed per 1000 person-years of follow-up.

f: $P$-values obtained for multiplicative interaction terms in the corresponding multivariable-adjusted Cox regression model. 
Table 6. Mortality rate and hazard ratios (HR) for total mortality and cardiovascular mortality in the PREDIMED participants according to the OGG1-rs1052133 polymorphism, after 4.8 years of median follow-up, depending on vegetable intake ${ }^{\mathrm{a}}$

Whole population $(\mathrm{n}=7,122)$

\begin{tabular}{|c|c|c|c|c|c|c|c|c|c|c|}
\hline & & & Model $1^{\mathrm{b}}$ & & & Model $2^{c}$ & & & Model $3^{\mathrm{d}}$ & \\
\hline $\begin{array}{l}\text { person- } \\
\text { years }\end{array}$ & $\begin{array}{l}\text { Mortality } \\
\text { rate }^{\mathrm{e}}\end{array}$ & HR & $95 \% \mathrm{CI}$ & $P$ & HR & $95 \% \mathrm{CI}$ & $P$ & HR & $95 \% \mathrm{CI}$ & $P$ \\
\hline
\end{tabular}

genotypes

Total mortality (deaths: 313 )

Vegetable intake (2 groups)

Low intake $(<314 \mathrm{~g} / \mathrm{d})(\mathrm{n}=3532)$

$\begin{array}{lccclcccccc}\text { Ser-carriers } & 165 / 14910 & 11.1 & 1.00 \text { (ref.) } & 1.00 \text { (ref.) } & 1.00 \text { (ref.) } \\ \text { Cys326Cys } & 14 / 650 & 21.5 & 2.01 & (1.16-3.49) & 0.013 & 1.97 & (1.14-3.41) & 0.016 & 1.92 & (1.16-3.36)\end{array}$

0.022

High intake $(>=314 \mathrm{~g} / \mathrm{d})(\mathrm{n}=3580)$

$\begin{array}{cccccccccccc}\text { Ser-carriers } & 126 / 14517 & 8.7 & 1.00 & \text { (ref.) } & & 1.00 & \text { (ref.) } & 1.00 & \text { (ref.) } \\ \text { Cys326Cys } & 8 / 639 & 12.5 & 1.36 & (0.66-2.79) & 0.407 & 1.43 & (0.69-2.93) & 0.333 & 1.37 & (0.66-2.81) & 0.395 \\ P \text { (interaction } & \text { OGG1 } x \text { Vegetable intake) } & & & & 0.446 & & 0.444 & 0.491\end{array}$

Vegetable intake (as continuous)

Interaction term OGG1 $x$ Vegetables

$0.75 \quad(0.45-1.25)$

$0.268 \quad 0.79 \quad(0.48-1.30)$

$0.360 \quad 0.80 \quad(0.49-1.30)$

0.367

Cardiovascular mortality (deaths: 80)

Vegetable intake (2 groups)

Low intake $(<314 \mathrm{~g} / \mathrm{d})(\mathrm{n}=3532)$

$$
\begin{aligned}
& \begin{array}{lllllll}
\text { Ser-carriers } & 39 / 14910 & 2.6 & 1.00 & \text { (ref.) } & 1.00 \text { (ref.) } & 1.00 \text { (ref.) }
\end{array} \\
& \begin{array}{llllllllllll}
\text { Cys326Cys } & 8 / 650 & 12.3 & 5.23 & (2.40-11.38) & <0.001 & 5.15 & (2.36-11.24) & <0.001 & 5.21 & (2.36-11.52) & <0.001
\end{array}
\end{aligned}
$$

High intake $(>=314 \mathrm{~g} / \mathrm{d})(\mathrm{n}=3580)$

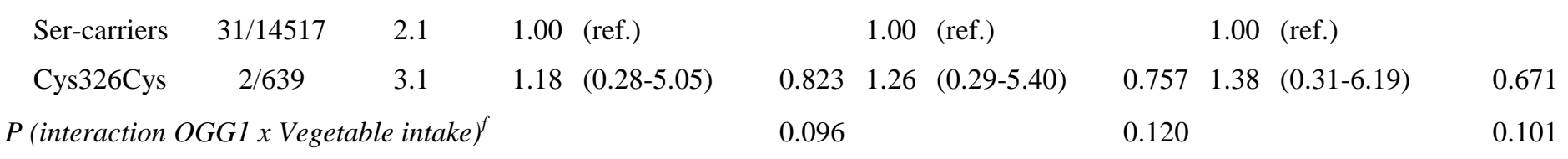

Vegetable intake (as continuous)

Interaction term OGG1 $x$ Vegetables $^{g}$

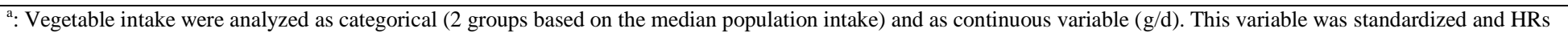

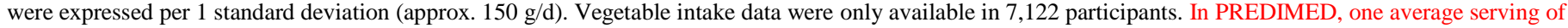
vegetables was estimated in $125 \mathrm{~g} / \mathrm{d}$. Then, $314 \mathrm{~g} / \mathrm{d}$ of vegetables are equivalent to $2.5 \mathrm{servings} / \mathrm{d}$.

b: Model 1: Adjusted for sex, age, center and dietary intervention group.

': Model 2: Adjusted for variables in model 1 plus body mass index, type-2 diabetes and self-reported cancer history at baseline.

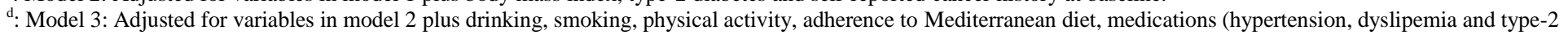
diabetes) and total energy intake at baseline.
} 
e: Mortality rates were expressed per 1000 person-years of follow-up.

f: $P$-values obtained for multiplicative interaction terms between the OGG1 genotype and vegetable intake, as categorical, in the corresponding multivariable-adjusted Cox regression model.

${ }^{g}$ : HR 95\% confidence interval and $P$-value for multiplicative interaction terms, between the OGG1 genotype and vegetable intake (as continuous), in the corresponding multivariable-adjusted Cox regression model. HRs are expressed per 1 standard deviation increase in vegetable intake. 